\title{
Relationships among physical properties as indicators of high temperature deformation or post-shock thermal annealing in ordinary chondrites.
}

Jon M. Friedrich ${ }^{1,2 \dagger}$, Alex Ruzicka ${ }^{3}$, Robert J. Macke ${ }^{6}$, James O. Thostenson ${ }^{4 \dagger}$, Rebecca A. Rudolph $^{4 \S}$, Mark L. Rivers ${ }^{5}$, Denton S. Ebel ${ }^{2,7,8}$ 
47 Abstract: Collisions and attendant shock compaction must have been important for the accretion and lithification of planetesimals, including the parent bodies of chondrites, but the conditions under which these occurred are not well constrained. A simple model for the compaction of

50 chondrites predicts that shock intensity as recorded by shock stage should be related to porosity

51 and grain fabric. To test this model, we studied sixteen ordinary chondrites of different groups

$52(\mathrm{H}, \mathrm{L}, \mathrm{LL})$ using X-ray computed microtomography $(\mu \mathrm{CT})$ to measure porosity and metal fabric,

53 ideal gas pycnometry and 3D laser scanning to determine porosity, and optical microscopy (OM)

54 to determine shock stage. These included a subsample of six chondrites previously studied using

55 transmission electron microscopy (TEM) to characterize microstructures in olivine. Combining

56 with previous data, results support the simple model in general, but not for chondrites with low

57 shock-porosity-foliation (low-SPF chondrites). These include Kernouvé (H6), Portales Valley

58 (H6/7), Butsura (H6), Park (L6), GRO 85209 (L6), Estacado (H6), MIL 99301 (LL6), Spade

59 (H6), and Queen's Mercy (H6), among others. The data for these meteorites are best explained

60 by high ambient heat during or after shock. Low-SPF chondrites tend to have older ${ }^{40} \mathrm{Ar} /{ }^{39} \mathrm{Ar}$

61 ages ( 4435-4526 Ma) than other, non-low-SPF type 6 chondrites in this study. We conclude

62 that the H, L, and LL asteroids all were shock-compacted at an early stage while warm, with

63 collisions occurring during metamorphic heating of the parent bodies. Results ultimately bear on

64 whether chondrite parent bodies have internal structures more akin to a metamorphosed onion

65 shell or metamorphosed rubble pile, and on the nature of accretion and lithification processes for 66 planetesimals.

67 Keywords: chondrites, shock, compaction, porosity, foliation, asteroids, annealing

68 running head: annealing and physical properties in ordinary chondrites 
Collisions were crucially important for the compaction of asteroidal-sized bodies,

71 including those from which ordinary chondrites were derived. Although endogenous radiogenic

$72\left({ }^{26} \mathrm{Al}\right.$ decay) heating alone would have resulted in some sintering (Henke et al., 2012), the parent

73 bodies would have retained significant amounts of ancient porosity following accretion, owing to

74 their small diameters. Lithostatic overpressure alone in a $\sim 100-300 \mathrm{~km}$ body is completely

75 insufficient for the reduction of remnant accretionary porosity (see Friedrich et al., 2014a for a

76 discussion). It has been shown by observation and experiment that high velocity impact

77 deformation alters the physical properties of materials in two ways: by reducing porosity, and by

78 introducing foliation, both as a result of compaction (Cain et al., 1986; Hirata et al., 2008;

79 Nakamura et al., 1995, 2000; Gattacceca et al., 2005; Friedrich et al., 2008a, 2008b, 2013,

80 2014b). During a collision on a high porosity (e.g. $>20-25 \%$ ) body, porosity is reduced, but in

81 low $(\leq 2-3 \%)$ porosity bodies, shock produces brittle cracking of silicates which actually

82 reintroduce porosity to a rock. Approximately 5-7\% porosity can be reintroduced by such

83 microcracking (Consolmagno et al., 2008). Thus, the structure of the porosity in a chondrite is as

84 important as the quantity of porosity for deciphering a chondrite's impact history. Foliation, or

85 planar preferred grain orientations, in ordinary chondrites has been observed and the strength of

86 foliation correlates with increasing shock intensity recorded in a rock (Sneyd et al., 1988;

87 Gattacceca et al., 2005; Friedrich et al., 2008a, 2014b). All of this leads to a simple model in

88 which shock intensity and metal shape foliation is inversely related to porosity (Fig. 1).

89 Separating a chondrite's history into discrete accretionary, thermal metamorphic, and

90 impact episodes is convenient, but the reality is much more complex. Ruzicka et al. (2015a)

91 examined olivine microstructures by transmission electron microscopy (TEM) and optical

92 microscopy (OM). They concluded that some chondrites experienced significant post-shock 
93 annealing (Ruzicka et al., 2015a), deformation while hot (Ruzicka et al., 2015a; Ashworth et al.,

94 1977), or both (Ruzicka et al., 2015a), consistent with other evidence for high-temperature

95 deformation (Friedrich et al., 2014a; Friedrich et al., 2013; Scott et al., 2014) and post-shock

96 annealing (Rubin, 2002; Rubin and Jones, 2003; Rubin, 2004; Friedrich et al., 2014a). ${ }^{40} \mathrm{Ar} /{ }^{39} \mathrm{Ar}$

97 ages in many of these chondrites date to the metamorphic era of ordinary chondrite history (e.g.,

98 Swindle et al., 2014). In reality, decoupling thermal metamorphism and impact may not be fully

99 realistic.

100 In this work, we test a simple model (Fig. 1) and reexamine the effects of shock 101 compression on porosity and foliation in ordinary chondrites in light of growing evidence for 102 complex relationships between impacts and thermal processes in these meteorites. Porosity, 103 foliation strength, and petrographic observations are used to interpret the thermal metamorphic104 shock histories of a suite of sixteen ordinary chondrites, including some of which are inferred to 105 have experienced either impact-related deformation at high temperatures or significant post106 shock annealing. The latter chondrites could have formed in asteroidal bodies near the base of a 107 crater or deeply buried within warm material. Our results have implications for parent body 108 structures and processes.

\section{SAMPLES AND METHODS}

\section{$110 \quad$ 2.1. Samples}

111 Sixteen equilibrated (type 6) ordinary chondrites were examined for this study. Samples

112 are listed in Table 1 with additional details shown in Supplementary Materials Table SM-1. Six

113 are either finds or Antarctic finds (Estacado, Morrow County, Park, Spade, GRO 85209 and MIL 114 99301) while the remainder are falls. 
115 Seven chondrites were selected because of previous evidence that they were either post-

116 shock-annealed or experienced shock-related deformation while at elevated temperatures. These

117 include: 1) Saint-Séverin (LL6) (Ashworth et al., 1977; Leroux et al., 1996); 2) Butsura (H6)

118 (Ashworth, 1981; Scott et al., 2014); 3) Portales Valley (H6/7) (Kring et al., 1999; Rubin, 2004;

119 Scott et al., 2014; Ruzicka et al., 2005; Ruzicka et al., 2015a); 4) Miller Range 99301 (hereafter

120 MIL 99301) (LL6) (Rubin, 2002, 2004; Friedrich et al., 2014a; Ruzicka et al., 2015a); 5)

121 Kernouvé (H6) (Rubin, 2004; Friedrich et al. 2013, Scott et al., 2014; Ruzicka et al., 2015a); 6)

122 Spade (H6) (Rubin and Jones, 2003; Rubin, 2004); and 7) Park (L6) (Ruzicka et al., 2015a).

123 Nine meteorites were selected for other reasons. These include chondrites that have a

124 variety of shock stages according to the Stöffler et al. (1993) shock stage scheme, or a variety of

$125{ }^{40} \mathrm{Ar} /{ }^{39} \mathrm{Ar}$ ages that indicate impacts occurring at different times, or that have evidence for "cold 126 deformation" which differs from the chondrites mentioned above. GRO 85209, Holbrook, 127 Alfianello, Tenham, Leedey, Bruderheim, and Morrow County are all L6 chondrites but vary in 128 shock stage (nominally S1 to S6). Three of these (Leedey, Bruderheim, and Morrow County) 129 showed evidence that shock deformation was initiated at low temperatures and was followed by 130 fast cooling (Ruzicka et al., 2015a). Four of the L6 chondrites have younger ${ }^{40} \mathrm{Ar} /{ }^{39} \mathrm{Ar}$ ages 131 (Leedey 3800 Ma; Bogard et al., 1987; Alfianello 1050 Ma; Kunz et al., 1997; Bruderheim 132 465 Ma; Turner, 1969; Morrow County 460 Ma; Ruzicka et al., 2015b), whereas Queen's 133 Mercy (H6) and Estacado (H6) have relatively old ( 4435-4490 Ma) ${ }^{40} \mathrm{Ar} /{ }^{39} \mathrm{Ar}$ ages (Turner et 134 al., 1978; Trieloff et al., 2003). Multiple ${ }^{40} \mathrm{Ar} /{ }^{39} \mathrm{Ar}$ ages were obtained for Saint-Séverin ( 4383, 135 4420 Ma; Hohenberg et al., 1981) and MIL 99301 ( 4230, 4520 Ma; Dixon et al., 2004) 136 suggesting more complex shock histories, but still dominated by older impacts.

$137 \quad$ 2.2. Methods 
$\mu \mathrm{CT}$ imaging was performed at two different facilities for this study. For some samples,

139 the GE phoenix v|tome|x s $240 \mu \mathrm{CT}$ system at the AMNH was used. This system is an instrument

140 employing polychromatic x-ray radiation generated by an $\mathrm{x}$-ray tube. Other samples were

141 imaged with monochromatic x-rays at beamline 13-BM-D at the GeoSoilEnviro Center for

142 Advanced Radiation Sources (GSE-CARS) at the Advanced Photon Source (APS) of Argonne

143 National Laboratory. Instrument-specific $\mu \mathrm{CT}$ analytical parameters and resolutions are listed in

144 detail within Table SM-1. Analytical resolutions ranged between 6-18 $\mu \mathrm{m} / \mathrm{voxel}$ (a voxel is a 3D

145 volume element akin to a 2D pixel or picture element). These resolutions yield interpretable data

146 and derived products that are comparable to data from all previous studies using the same

147 methodology (e.g. Friedrich et al., 2014b and references therein).

148 The 3D method presented in Friedrich et al. (2008a) and elaborated on in Friedrich et al.

149 (2013) was used to quantify the magnitude of foliation of the metal grains in each $\mu \mathrm{CT}$ volume.

150 This method produces a numerical value for the strength factor, C (Woodcock, 1977; Woodcock

151 and Naylor, 1983). The higher the numerical strength factor, the more pronounced the common

152 orientation of the metal grains and the greater the foliation.

153 For some of our samples, two distinct chips were examined with $\mu \mathrm{CT}$. Leedey was 154 examined in Friedrich et al. (2008a) and an additional sample was examined with $\mu \mathrm{CT}$ for this 155 work (Table 1). Kernouvé was analyzed with $\mu \mathrm{CT}$ in duplicate for a previous study (Friedrich et 156 al., 2013) and the two samples of MIL 99301 are the same samples that were reported on in 157 Friedrich et al. (2014a); however, new data (foliation strength) are presented for MIL 99301. All 158 of these duplicate data are included in Table 1 to allow for the evaluation of inter-sample 159 variation of foliation strength (Sec. 3). 
Bulk porosity measurements of four samples (Morrow County, Park, Spade, Saint-

161 Séverin) for this work were accomplished via a combination of ideal gas pycnometry and laser

162 scanning. Ideal-gas pycnometry utilizing a Quantachrome Ultrapycnometer 1000 pressurized

163 with $\mathrm{N}_{2}$ gas, provided grain density ( $\rho_{\mathrm{g}}$ ) (cf. Consolmagno et al., 2006; Macke, 2010). Using a

164 NextEngine ScannerHD Pro laser scanner, computer shape models were produced for each

165 sample, from which the bulk volume and density $\left(\rho_{b}\right)$ were determined (Macke et al., 2015).

166 Porosity was calculated from these two quantities: $P=1-\left(\rho_{b} / \rho_{g}\right)$. For four samples (Butsura,

167 GRO 85209, Portales Valley, Queen's Mercy; see Tables 1 \& SM-1), porosity was quantified

168 using the $\mu$ CT-based methods described in Friedrich and Rivers (2013). Friedrich and Rivers

169 (2013) demonstrated that high resolution $(2.6 \mu \mathrm{m} /$ voxel edge, Table SM-1) $\mu \mathrm{CT}$ imaging and

170 digital quantification of porosity yields completely comparable results to ideal gas pycnometry.

171 Other porosity values were taken from the exhaustive Macke (2010) database (see Table 1, 2). In

172 cases of ordinary chondrite finds, the model porosity was used, determined from the sample's

173 measured bulk density and the average grain density for typical falls of that type, rather than the

174 measured porosity to compensate for any potential terrestrial alteration effects (see Consolmagno

175 et al., 2008). Errors for porosity are reported only for those samples that were measured for this

176 study (Table 1). This is because errors for most previous results from Macke (2010) are not

177 directly comparable to our own since the previous results are generally the mean of several to

178 many individual analyses. A direct comparison may be misleading. A typical error for porosity

179 measurements is on the order of $5-25 \%$ relative, with the majority of our samples possessing

180 errors of $<10 \%$ (see Macke, 2010). Using the porosity errors for samples in this study (Table 1),

181 the average of the errors is $0.82 \%$ absolute. This can be taken as a representative error for

182 porosity that reflects some combination of analytical precision and sample heterogeneity. 
Optical microscopy (OM) of petrographic thin sections was used to determine the shock

184 stage of each sample using the method of Stöffler et al. (1991). Conventional shock stage is

185 determined by the highest shock stage shown by at least $25 \%$ of olivine grains measured

186 (Stöffler et al., 1991). A mean shock stage ("weighted shock stage") was also determined by

187 averaging the inferred shock stages for a large number of (typically $\mathrm{N}>100$ ) olivine grains,

188 following the procedure of Jamsja and Ruzicka (2010) and Ruzicka et al. (2015a). In cases where

189 there is significant variation between grains, the conventional shock stage can be misleading in

190 part owing to the $25 \%$ rule, and the weighted shock stage can better represent the overall optical

191 deformation of olivine. Moreover, large variations in grain shock stages also can allow the

192 identification of breccias and multiple impacts. Finally, we searched for olivine grains with low

193 strain (minimal extinction variations in cross-polarized light) but containing low-angle subgrain

194 boundaries (sharp changes in misorientation across well-defined boundaries) which can be an

195 optical manifestation of microstructural recovery and annealing (Ruzicka et al., 2015a).

\section{RESULTS}

197 Shock stage classifications are shown in Table 1, and histograms of shock stages for 198 individual olivine grains within each chondrite are shown in Fig. 2. Shock stage data indicate 199 that some meteorites are breccias composed of a wide mix of individual grain shock stages. This 200 includes Holbrook (S1- thru S4-dominant), Saint-Séverin (diverse, but S2- thru S4-dominant), 201 Spade (bimodal, S1/S2- and S4-dominant), and Butsura and MIL 99301 (S1-dominant but 202 containing admixtures of more highly shocked material) (Fig. 2). Saint-Séverin also displays an 203 obvious brecciated (clastic) texture. Such shock-heterogeneous chondrites are listed in Table 1 204 with asterisks next to their shock stages. 
Other chondrites have more uniform shock stages. Good examples of these include

206 Kernouvé and Portales Valley (predominantly S1), Leedey (predominantly S4), and Tenham and

207 Morrow County (predominantly S4 and S5) (Fig. 2).

208 Depending on whether they are heterogeneous or uniform in shock stages, chondrites

209 thus have larger or smaller values of standard deviations in weighted shock stages (Table 1). An

210 average of the standard deviations gives 0.42 , which can be taken as a representative overall

211 "error" in weighted shock stage for the meteorites in this study, caused primarily by sample

212 heterogeneity.

213 Foliation strength factor, C, values for each sample are shown in Table 1. C values range

214 from 0.03 (GRO 85209) to 1.13 (Alfianello), nearly spanning the range previously measured for

215 ordinary chondrites (Table 2). Three of the meteorites examined in this study have multiple

216 samples examined for petrofabrics with $\mu \mathrm{CT}$. This gives an opportunity for the examination of

217 the variability that may be expected for different chips from the same stone. From the duplicate

218 measurements, the largest absolute difference $(\Delta=0.15)$ can be found between the two Leedey

219 samples, where the determined $\mathrm{C}$ values are 0.51 and 0.66 . The other samples in this study for

220 which we have replicate data (Kernouvé, MIL 99301) give even more consistent results $(\Delta=0.08$

221 and 0.03 respectively, Table 1). One literature compilation sample, Saratov, has had five

222 replicate fabric analyses performed (see Table 2) and the standard deviation of the $\mathrm{C}$ value for

223 them is $16 \%$ relative standard deviation (RSD). Taking all available data into account (Table 1,

224 2), the average of standard deviation values for $\mathrm{C}$ in a given meteorite is 0.027 . This can be taken

225 as a representative "error" for C, which largely reflects sample heterogeneity. Given that this

226 "error" is much less than the total range in $\mathrm{C}$ among different meteorites, $\mathrm{C}$ values can be taken

227 as representative of the stones as a whole. 
Figure 3 shows stereoplots for metal grain orientations in four chondrites that have

229 different values of $\mathrm{C}$ (but similar porosity). The stereoplots show the direction of long axes of

230 metal grains in three dimensions. With increasing value of $\mathrm{C}$, the long axes of different grains

231 become progressively concentrated in a plane (Fig. 3). This indicates that the C value can be

232 taken as a measure of foliation strength in metal grains.

233 Figure 4 shows the relationship between the degree of metal foliation and shock stage

234 (both conventional and weighted). As previously demonstrated by Friedrich et al. (2008a) and

235 others (Gattacceca et al., 2005; Sneyd et al., 1988), there is a correlation between foliation and

236 the shock stage of a sample: with increasing shock stage, metal grains are more foliated. Spade

237 and Saint-Séverin have perhaps a lower C value than may be expected when $\mathrm{C}$ is plotted against

238 conventional shock stage (Fig. 4a), but appear less anomalous when $\mathrm{C}$ is plotted against

239 weighted shock stage (Fig. 4b). Overall, these results conform to what is expected for the simple

240 model (Fig. 1).

241 Porosity data are given in Tables 1 and 2 . Porosities vary from $\sim 0.5-9.9 \%$ for new

242 measurements and between $\sim 0.5-20.0 \%$ among all the ordinary chondrites. The relationship

243 between porosity and shock stage (both conventional and weighted) is shown in Fig. 5.

244 Consolmagno et al. (2008) demonstrated that there is a general trend of lower porosity with

245 increased shock stage. However, they noted that while it is true to say that no high shock stage

246 ordinary chondrites possess high porosity, some ordinary chondrites with low shock stages

247 possess low porosity. This conclusion is consistent with the data obtained here. Namely, some

248 chondrites with low shock stage (conventional and weighted) have relatively low porosities

249 (<10\%), similar to those of chondrites with high shock stages (Fig. 5). These results do not

250 entirely conform to the simple model (Fig. 1). 
Finally, the relationship between porosity and foliation strength $\mathrm{C}$ is shown in Fig. 6 .

252 Although there are no meteorites that have both high foliation strength and high porosities, and

253 although the most porous chondrites have the lowest foliation strengths, there are also chondrites

254 that have both low porosity and low foliation strength (Fig. 6). These results again do not entirely 255 conform to the simple model (Fig. 1).

\section{DISCUSSION}

$257 \quad 4.1$ Evidence for additional variables in shock deformation

Although the new data collected support the idea that shock deformation caused both a

259 flattening of metal grains to create a foliation, as well as a collapse of pores to reduce overall

260 porosity, there is evidence that the situation may be more complex than at first appears, with

261 additional variables being important. Support for flattening is given by the general positive

262 relationship between shock stage and orientation strength parameter C (Fig. 4), with the long

263 axes of metal grains becoming concentrated in a plane (Fig. 3). Support for pore collapse is given

264 by the general inverse relationship between porosity and shock stage (Fig. 5a). However, there is

265 considerable scatter in both foliation and porosity for a given shock stage. Of particular note is

266 the substantial variation in porosity shown by different S1 shock stage chondrites, ranging

267 between $\sim 0.5-20 \%$ (Fig. 5a). Higher porosity values could indicate the little shock compression

268 expected by a weak shock, but there is no a priori reason to expect low porosity for some S1

269 chondrites. Moreover, shock compaction should produce an inverse relationship between metal

270 foliation and porosity (Fig. 1), but there is again no a priori reason to expect the occurrence of

271 chondrites with both low porosity and low metal foliation (Fig. 6). If a chondrite has experienced

272 an impact intense enough to remove porosity, an intense foliation would be expected.

273 Brecciation effects can complicate interpretations as materials with different shock stages can 
274 become mixed. However, Macke (2010) found little difference between porosities of brecciated

275 and unbrecciated ordinary chondrites. Moreover, even with brecciation and mixing of materials

276 with different shock stages, one might expect an inverse relationship between porosity and

277 weighted shock stage. However, no such inverse relationship is evident (Fig. 5b).

278 Thus, there is evidence that the "simple model" for shock deformation (Fig. 1) is

279 oversimplified, and that additional factors must be important. Two likely important variables not

280 considered in simpler models are 1) the extent of post-shock annealing and 2) the ambient

281 temperature of deformation. Both may be related to the amount of ambient heat in the parent

282 body. Both could be explained by impact events occurring on parent bodies that were being

283 metamorphosed.

284 Elevated post-shock temperatures can potentially anneal once-oriented metal grains in the 285 target materials to destroy petrofabrics. There is evidence in $\mathrm{H}$ chondrites for increasing 286 sphericity and size of metal grains with an increase in petrographic type (Guignard and Toplis, 287 2015), suggesting that petrofabrics will be destroyed if post-shock annealing conditions are 288 similar to those involved in thermal metamorphism, as could be the case if shock occurred during 289 thermal metamorphism. Moreover, there is mounting evidence that post-shock annealing of 290 chondrites can lessen apparent shock stages by decreasing optical strain in olivine (e.g., Rubin 291 2002, 2004; Rubin and Jones, 2003; Ruzicka et al., 2015a). Although it is conceivable that 292 annealing could reduce porosity by allowing minerals to grow into pore spaces or by facilitating 293 pore collapse, the latter process would be limited by lithostatic overburden pressures insufficient 294 for complete pore collapse. Thus, post-shock annealing can potentially affect metal fabric and 295 olivine shock stage, but porosity should be much less affected by annealing. The effect of post- 
296 shock annealing will be to shift chondrites to lower foliation and shock stage than they would 297 otherwise have, i.e., to the left in Fig. 1, 5, and 6, and to the lower left in Fig. 4.

298 Besides annealing, pre-shock temperature could be an important variable. Shock loading

299 experiments show that if pre-shock temperature is elevated, foliation increases and porosity 300 decreases for a given shock pressure (Nakamura et al., 2000). Elevated pre-shock temperatures 301 can affect how minerals respond to deformation, although optical deformation effects for olivine 302 do not change drastically for shock experiments performed over a wide range of pre-heating 303 temperatures (293 K to $920 \mathrm{~K}$ ) (Schmitt, 2000). Therefore, the effect of elevated pre-shock 304 temperature will be to shift chondrites to lower porosities and higher foliations than they would 305 otherwise have, i.e., downwards in Fig. 1 and 5, upwards in Fig. 4, and to the lower right in Fig. 3066.

The role of brecciation and multiple impacts is discussed further in Sec. 4.4, but here it is 308 useful to point out that these effects probably cannot explain chondrites with a combination of 309 low shock stage, porosity, and foliation. In general, multiple impacts will cause extra compaction 310 and a decrease in porosity (Nakamura et al., 2000), simulating the effect of fewer but stronger 311 impacts. However, foliation mostly responds to the last strong impact (Friedrich et al., 2014b), so 312 foliation might not change much unless subsequent impacts were stronger than what came 313 before. Shock damage will be cumulative. In general, therefore, one would expect multiple shock 314 events to have the effect of decreasing porosity, increasing shock stage somewhat, and having 315 little effect on foliation in many cases. However, this does not readily explain chondrites that 316 have low shock stage, low porosity, and low metal foliation. To explain such chondrites, some 317 combination of post-shock annealing and elevated pre-shock temperature are more promising 318 explanations. 


\subsection{Two groups of chondrites and their significance}

320

321

322

323

324

325

326

327

328

329

330

331

332

333

334

335

336

337

338

339

340

341

Results suggest that chondrites can be subdivided into at least two groups based on their physical properties and shock stages. One group does not conform to the simple model for shock deformation and is here termed the "low-SPF group" (for low shock-porosity-foliation). The other group conforms to what is expected for the simple model and is here termed simply the "non-low-SPF group". Table 3 identifies chondrites as belonging to one group or the other based on available data. In Fig. 5 and 6, dashed guidelines separate the two groups, with low-SPF chondrites having relatively low porosity for a given shock stage (Fig. 5), and having both low porosity and low metal foliation (Fig. 6). The exact placement of the guidelines in these figures is somewhat arbitrary. However, as shown in Table 3 and Fig. 5 and 6, there is substantial overlap in groupings based on 1) low shock stage and low porosity, and 2) low porosity and low metal foliation. This suggests that low-SPF chondrites form a relatively coherent group, with different combinations of properties largely identifying the same group of meteorites. By extension, non-low-SPF chondrites (anything that is not in the low-SPF group) also form a relatively coherent group. However, there is some ambiguity for group assignments, especially for those chondrites that have intermediate shock stages, porosities, and metal foliations.

The best explanation for creating a low-SPF chondrite is some combination of post-shock annealing and elevated pre-shock temperature (Sec. 4.1). This inference is consistent with other data for these chondrites, as discussed in more detail in Sec. 4.3 and below.

Some chondrites assigned to the low-SPF group show especially good evidence for annealing or high-temperature deformation. These include Estacado, Kernouvé, MIL 99301, Portales Valley, Spade, and Park. All but Park have a significant number of optically visible subgrain boundaries in olivine that could signify post-shock annealing, and even Park has some 
342 of these subgrain boundaries (Table 1). In Kernouvé, MIL 99301, and Portales Valley, TEM

343 evidence indeed suggests that subgrain boundaries were produced by annealing (Ruzicka et al.,

344 2015a). In Kernouvé, MIL 99301, and Park, TEM evidence suggests that deformation occurred

345 under conditions of elevated pre-shock temperature (Ruzicka et al., 2015a). Using the best

346 available data, these various low-SPF chondrites are coded in Fig. 4-6 according to whether they

347 are annealed (Estacado, Portales Valley, Spade), hot-deformed (Park), or both annealed and hot-

348 deformed (Kernouvé, MIL 99301).

349 Other chondrites assigned to the low-SPF group include GRO 85209, Butsura, Tjerebon,

350 and possibly Queen's Mercy and L'Aigle (Table 3). Currently it is not known for certain whether

351 these chondrites were annealed or hot-deformed, so they are coded in Fig. 4-6 as "other low-

352 SPF" chondrites, although there is some evidence for both annealing and hot deformation in

353 Butsura (Sec. 4.3.5). Bath Furnace has relatively low porosity and metal foliation but no shock

354 stage determination, so it is unclear whether it is a low-SPF chondrite (Table 3).

355 In contrast, many other meteorites belong to the non-low-SPF group (Table 3). This

356 includes the L6 chondrites Alfianello, Bruderheim, Holbrook, Leedey, Morrow County, and

357 Tenham. There is reason to suppose that they were shocked on a cold parent body. None show

358 obvious subgrain boundaries that can be attributed to annealing. Prior TEM work (Ruzicka et al.,

359 2015a and references therein) suggested that at least Bruderheim, Leedey, and Morrow County

360 experienced relatively simple or idealized shock histories: their predominant shock deformation

361 was initiated at low temperatures and was followed by fast cooling. Furthermore, these impacts

362 occurred far later than the time thermal metamorphism was active on the parent asteroid and so

363 must have occurred when the asteroids were cold. For instance, ${ }^{40} \mathrm{Ar} /{ }^{39} \mathrm{Ar}$ ages for Leedey $(3800$

$364 \pm 100 \mathrm{Ma})$ (Bogard et al. 1987), Bruderheim (465 $\pm 30 \mathrm{Ma}$ ) (Turner et al., 1966, Turner, 1969), 
365 and Morrow County (460 $\pm 10 \mathrm{Ma}$ ) (Ruzicka et al., 2015b) suggest late impact events on the L

366 chondrite parent body, with the latter two ages corresponding to the inferred break-up event of

367 the L asteroid (e.g., Swindle et al., 2014). Similarly, Alfianello ( ${ }^{40} \mathrm{Ar} /{ }^{39} \mathrm{Ar}$ age $1050 \pm 60 \mathrm{Ma}$;

368 Kunz et al., 1997) and Tenham are strongly shocked (S5) chondrites in which shock and related

369 (re)heating episodes appear to have occurred in a post-metamorphic setting. Although the

$370{ }^{40} \mathrm{Ar} /{ }^{39} \mathrm{Ar}$ age of Holbrook potentially dates to a metamorphic era (4400 $\left.\pm 100 \mathrm{Ma}\right)$, it seems to

371 be a non-low-SPF chondrite based on somewhat elevated values of shock stage and foliation

372 strength, and a porosity that is not overly low for the given shock stage and foliation (Fig. 5, 6).

373 Barratta (L4) probably also belongs to the non-low-SPF group as it has a somewhat high

374 conventional shock stage of S4, although it does have somewhat low porosity and metal foliation

375 (Fig. 6). Saint-Séverin (LL6) likewise appears to belong to this group (Table 3), although it may

376 have been shocked while warm (Ashworth et al., 1977).

377 4.3. Annealed or hot-deformed chondrites

378 We assign Kernouvé, Portales Valley, GRO 85209, Park, Butsura, Estacado, MIL 99301,

379 Spade, and Queen's Mercy to the group of chondrites that exhibit a combination of relatively low

380 shock stages, low porosities, and low metal foliations (low-SPF group, Table 3), which could

381 reflect post-shock annealing or deformation while hot (Sec. 4.1, 4.2). In agreement with this,

382 most of these chondrites, along with Saint-Séverin, were previously suggested based on various

383 data to have been annealed following shock or deformed while warm (Sec. 2.1). The shock

384 histories of these meteorites are discussed individually below.

385 4.3.1. Kernouvé

386 Kernouvé is an H6 chondrite with an S1 shock stage. The relatively low porosity of 387 Kernouvé (5.8\%) is in the form of intergranular voids rather than intragranular cracks (Friedrich 
388 et al. 2013). In Kernouvé the intergranular voids are likely the remains of incomplete compaction

389 during impact, in contrast to intragranular cracks that are generally interpreted as being produced

390 after full compaction and subsequent cracking of the brittle silicates (Friedrich and Rivers, 2013;

391 Consolmagno et al., 2008). Despite such incomplete compaction, preferred orientation of the 392 metal grains is minimal (Fig. 6).

393 Based on an old ${ }^{40} \mathrm{Ar} /{ }^{39} \mathrm{Ar}$ age and the presence of coarse metal veins that could have 394 formed by shock melting, Rubin (2004) hypothesized that Kernouvé was impacted and then 395 annealed during thermal metamorphism. Friedrich et al. (2013) came to a similar conclusion 396 regarding the timing and nature of the impact-related compaction experienced by Kernouvé. As 397 they found no significant collective orientation of metal grains they concluded that high 398 metamorphic temperatures following compaction erased any common orientation of metal grains 399 due to compaction. Furthermore, a coarse metal vein imaged in 3D by these authors was 400 interpreted as showing evidence for formation by shear and subsequent grain growth during 401 metamorphism. Scott et al. (2014) also suggested that Kernouvé could have been impacted 402 during metamorphism of the $\mathrm{H}$ chondrite parent body. Their inferred metallographic cooling rate 403 of $10{ }^{\circ} \mathrm{C} / \mathrm{Ma}$ for Kernouvé is one of the lower values they obtained for $\mathrm{H}$ chondrites and suggests 404 low-temperature annealing as a result of deep burial. Ruzicka et al. (2015a) inferred slow post405 shock cooling for the meteorite at a higher temperature, sufficient to allow migration of 406 dislocations in olivine into subgrain boundaries. These authors also found evidence for shock 407 occurring at an elevated temperature, but no evidence that Kernouvé was ever shocked above an 408 S1 shock stage level.

409 Kernouvé thus appears to have been weakly shocked at high temperature during thermal 410 metamorphism to form metal veins, and to have cooled slowly from metamorphic temperatures. 
411 The moderately low porosity (Fig. 5, 6) suggests some pore collapse caused by only a weak or

412 moderate shock pressure, perhaps aided by high temperatures. The very low foliation suggests

413 considerable annealing to obliterate any early metal fabric and to modify the metal veins. Most

414 likely Kernouvé formed and cooled in hot basement materials on the H-chondrite asteroid, and 415 experienced at least some shock compaction while warm.

\section{4.3.2. Portales Valley}

417 Portales Valley is an H chondrite with distinctive coarse metal veins (Kring et al., 1999)

418 and has the lowest measured porosity $(0.5 \%)$ of any of the chondrites shown in Fig. 5 and 6 . This

419 porosity measurement only includes the silicate fraction and does not include the coarse metal

420 vein material, so the low porosity value is even more striking as metal would be expected to have

421 low porosity. Using the Stöffler et al. (1991) scheme, Portales Valley is clearly within the lowest

422 shocked (S1) category based on olivine; however, the extensive metal veining in Portales Valley

423 has been interpreted as being due to shock mobilization associated with impact cratering on the

424 H chondrite asteroid (Kring et al., 1999; Rubin, 2004; Ruzicka et al., 2005). A fine

425 Widmanstätten structure in coarse metal and cooling models for zoned taenite grains indicate

426 that Portales Valley cooled slowly at low temperatures after impact (Kring et al., 1999; Ruzicka

427 et al, 2005; Scott et al., 2014). Moreover, well-developed subgrain boundaries in olivine were

428 interpreted as evidence of slow post-shock cooling at elevated temperatures (Ruzicka et al.,

429 2015a). Unlike the situation for Kernouvé, the latter authors found evidence that olivine in

430 Portales Valley was significantly deformed prior to annealing. Dislocation densities in vestigial

431 heavily-deformed areas are comparable to that found in S4 to S5 chondrites, leading Ruzicka et

432 al. (2015a) to conclude that the original olivine shock stage for Portales Valley prior to recovery

433 could have been as high as S4 or S5, although the precise shock intensity was uncertain. The 
434 meteorite could have been close to peak metamorphic temperature at the time of impact (Ruzicka

435 et al., 2005; Scott et al., 2014), a possibility that is consistent with (but not necessarily demanded

436 by) olivine microstructural data (Ruzicka et al., 2015a). Thus, extensive annealing following

437 possibly high-temperature deformation is suggested for Portales Valley.

438 Porosity and metal foliation data for Portales Valley are consistent with an important role

439 for annealing and high-temperature deformation. The very low porosity of Portales Valley is

440 consistent with a strong shock ( $\geq \mathrm{S} 4)$ occurring at high temperature to result in maximal pore

441 collapse (Fig. 1, 5). Annealing during slow post-shock cooling was likely responsible for

442 producing both the low shock stage and low amount of metal foliation of the meteorite, involving

443 both a significant decrease in apparent shock stage and a decrease in foliation strength (Fig. 1, 4).

444 For an initial shock stage of S4 or S5 that was reduced to S1, the foliation strength could have 445 been decreased dramatically ( $\mathrm{C}$ from $\sim 0.5-1.1$ to $\sim 0.15$, Fig. 4 ). All data support the idea that

446 Portales Valley formed and cooled in warm basement materials on the $\mathrm{H}$ chondrite asteroid 447 below an impact crater.

448 4.3.3. GRO 85209

449 GRO 85209 was included in our study as a representative of an L6 chondrite with an 450 uncommon (for L chondrites) S1 shock stage. Our data indicate that GRO 85209 has both low 451 porosity $(2.2 \%)$ and also a near lack of foliation in the metal grains. In terms of shock stage, 452 porosity, and metal foliation, GRO 85209 is similar to Kernouvé and Portales Valley (Fig. 4a, 5a, 453 6), and so could have formed in a similar manner, although on a different parent body (L instead 454 of $\mathrm{H})$. Although few other studies on GRO 85209 exist for comparison, we propose that based on 455 the relationships among physical properties, GRO 85209 was likely annealed to a high degree 456 after a substantial impact at elevated temperature that removed much of the porosity. 
474 low degree of preferred metal orientation could be partly the result of a weak shock to begin

\subsubsection{Park}

As with GRO 85209, Park is an L6 chondrite with a low (for an L chondrite) S1 shock stage. OM data confirm the S1 designation (Table 1). Some subgrain boundaries in olivine are visible optically (Table 1), suggestive of annealing, but little evidence for post-shock annealing was noted with TEM (Ruzicka et al., 2015a). TEM observations of olivine microstructures showed that Park experienced mild deformation at high temperatures (Ruzicka et al., 2015a). Olivine microstructures for Park together with a precise ${ }^{40} \mathrm{Ar} /{ }^{39} \mathrm{Ar}$ age of $4528.8 \pm 4.6 \mathrm{Ma}$ (Ruzicka et al. 2015b) were interpreted to indicate early deformation followed by relatively rapid cooling, with Park impact-excavated to a shallower level of a warm parent body (Ruzicka et al., 2015a, 2015b).

Park has moderately low porosity and a low degree of metal foliation (Fig. 5, 6). The porosity in Park is dominated by intergranular porosity with few intragranular microcracks. On a porosity - shock stage plot (Fig. 5), the porosity of Park is more like that of a typical S2 or S3 chondrite, but based on OM and TEM data it does not seem likely that strain in olivine consistent with S2-S3 levels was obliterated by annealing to make an S1 level (Ruzicka et al., 2015a). Rather, the low porosity for Park can be explained by relatively weak (S1) high-temperature deformation promoting more compaction that would otherwise be the case for a cold target. The with, but given that foliation is lower in Park than many other S1 chondrites (Fig. 4, 6), it seems likely that post-shock annealing obliterated preferred orientation for metal. If so, post-shock cooling was not overly rapid, and Park may not have been excavated to the very surface of the parent body, but rather to a shallow, somewhat cooler level than in which it originally formed.

\subsubsection{Butsura}


Butsura (H6) is classified as shock stage S1. Ashworth (1981) found that although shock

481 effects in Butsura were inhomogeneous within the brecciated (Table 1) sample, there was 482 evidence of some annealing of olivine after deformation. An ancient ${ }^{40} \mathrm{Ar} /{ }^{39} \mathrm{Ar}$ age for Butsura 483 (4480 $\pm 30 \mathrm{Ma}$; Turner et al., 1978) suggests the shock-related deformation occurred during 484 metamorphism, as a later shock event and the elevated thermal temperatures associated with it 485 would have been recorded by the ${ }^{40} \mathrm{Ar}-{ }^{39} \mathrm{Ar}$ system. Much like Kernouvé (Sec. 4.3.1), Butsura 486 has a $\sim 30 \mathrm{~cm}$ long millimeter-wide vein of metallic Fe-Ni (Hutchison, 2004). Such veins are 487 nearly identical to those seen in Kernouvé, which were hypothesized to be due to pre- or syn488 metamorphic impact-related deformation (Friedrich et al., 2013; Scott et al., 2014). Using 489 metallographic techniques, Scott et al. (2014) found a relatively slow $\left(10-100{ }^{\circ} \mathrm{C} / \mathrm{Myr}\right)$ cooling 490 rate for Butsura, which suggests deep burial within the parent body.

491 The $6.6 \%$ porosity contained in Butsura is lower than would be expected for an ordinary 492 chondrite of S1 shock stage (Fig. 5) and could indicate that over half of the primordial porosity 493 of Butsura was removed. However, this compaction is not reflected in terms of appreciably 494 higher foliation strength (Fig. 6). The porosity structure of Butsura is identical to that seen in 495 Kernouvé (see Friedrich et al., 2013): intergranular, due to incomplete compaction.

496 Thus, it appears that Butsura was shocked early, possibly at high temperature, and cooled 497 slowly afterwards at depth in the $\mathrm{H}$ chondrite asteroid. The impact removed some porosity and 498 somewhat oriented the metal grains. However, the deep burial and slow cooling annealed olivine 499 deformation and partially removed preferred orientation in the metal grains. As with Kernouvé 500 and Portales Valley, Butsura likely formed beneath an impact crater on the $\mathrm{H}$ chondrite parent 501 body.

502 4.3.6. Estacado 
Like Butsura, Estacado is an H6 chondrite. $\mu \mathrm{CT}$ investigation of the porosity shows the

504 majority of the $4.3 \%$ porosity is intergranular, again suggesting incomplete compaction rather

505 than porosity due to shock-induced microcracks within silicate grains. The metal foliation seen in

506 Estacado is the highest known for an S1 chondrite (Fig. 4). This foliation strength is strong

507 enough to be matched by chondrites of shock stage S2 or S3 (Fig. 4). Estacado possesses a

508 porosity of only $4.3 \%$, which is about one-third of what may be expected for a chondrite of S1

509 shock stage (Fig. 5a). If we were to consider only the porosity and degree of foliation of

510 Estacado, a reasonable estimate for the shock stage would be S3 (Fig. 4, 5). However, our S1

511 classification of Estacado's shock stage is corroborated with others' assessments (Rubin, 2004;

512 Scott et al., 2014). Given the low shock stage and strong foliation for an S1 chondrite,

513 compaction of materials that were already warm followed by post-shock annealing to lessen

514 olivine deformation could explain the data. Annealing is supported by optical identification of

515 subgrain boundaries in Estacado olivine (Table 1) similar to that produced by recovery.

516 However, annealing could not have been overly extensive, for otherwise one would expect this to

517 have destroyed metal foliation.

518 4.3.7. MIL 99301

519 MIL 99301 (LL6) has been extensively studied (Rubin, 2002, 2004; Friedrich et al., 520 2014a; Ruzicka et al., 2015a). Two Ar ages are recorded for the meteorite, 4520 and $4230 \mathrm{Ma}$

521 (Dixon et al., 2004). Based on potential petrographic shock indicators, Rubin (2002, 2004)

522 concluded that MIL 99301 was shocked to high $(\sim \mathrm{S} 4)$ levels, and later annealed, possibly due to

523 post-metamorphic impact heating. Friedrich et al. (2014a) examined MIL 99301, noted its

524 substantial porosity in the form of intergranular voids, and suggested that impacts into materials

525 that were already hot may have produced the relict shock indicators noted by Rubin $(2002,2004)$ 
526 and Friedrich et al. (2014a). Ruzicka et al. (2015a) found microstructural evidence in olivine

527 both for high-temperature deformation and post-shock annealing. They suggested that MIL

52899301 olivine could have experienced significant recovery, possibly lessening the shock stage

529 from $\sim \mathrm{S} 2-\mathrm{S} 3$ to $\mathrm{S} 1$.

530 Considering MIL 99301 in the context of this work, the porosity of the meteorite is

531 somewhat intermediate between low-SPF and non-low-SPF S1 chondrites (Fig. 5a). The porosity

532 is appropriate for what one would expect for S2 or S3 chondrites (Fig. 5), so shock of this

533 intensity followed by annealing and recovery of olivine to S1 shock stage could explain both the

534 porosity and olivine data. The foliation strength of MIL 99301 is at the low end of foliations

535 known for ordinary chondrites, and lower than S2 and S3 as well as higher shock stage

536 chondrites (Fig. 4). This suggests that metal foliation in MIL 99301 was largely eliminated by

537 the same annealing event that affected olivine. Thus, MIL 99301 could have been shocked while

538 warm and then annealed, with the latter process being especially important for olivine recovery

539 and reducing metal foliation. Cooling likely occurred at depth in the warm LL parent asteroid. At

540 a later stage, possibly at $\sim 4230 \mathrm{Ma}$ ago, a small proportion of more highly shocked material

541 could have been incorporated into the MIL 99301 source area to account for its presence in the

542 rock (Ruzicka et al., 2015a) (Table 1, Fig. 2h), but any later impacts evidently did not introduce

543 much microcracking nor result in metal foliation.

544 4.3.8. Spade

545 Spade is an H6 chondrite. Rubin and Jones (2003) and Rubin (2004) shock-classified

546 Spade and found a shock stage of S2, which differs from our own shock stage classification of

547 S4. The latter is somewhat misleading, however, as the weighted shock stage for Spade is only

5482.39 (Table 1), which is similar to the Rubin and Jones (2003) and Rubin (2004) conventional 
549 shock value. Our OM data suggest that Spade is actually an S1-S2, S4 bimodal breccia, with

$55038 \%, 23 \%$, and $32 \%$ of olivine grains consistent with shock stages of S1, S2, and S4 respectively

551 (Fig. 2n). These grains of different shock stages are intimately mixed. The previous investigators

552 found that Spade was best described as an annealed impact melt breccia. The brecciated nature of

553 Spade and how one designates conventional shock stage for such breccias likely accounts for the

554 differences in classification between the investigations.

555 For Spade, porosity and metal foliation strength factor are both low compared to other

556 chondrites, but not overly so (Fig. 6). Much of the porosity is in the form of microcracks. Spade

557 also shows optical evidence for subgrain boundaries in olivine (Table 1), consistent with 558 annealing.

559 Our interpretation for Spade superficially agrees with that of Rubin and Jones (2003): the

560 meteorite was shocked, which reduced its porosity and oriented the metal grains, but some

561 degree of annealing removed the high degree of orientation to what we see today. This annealing 562 also resulted in some olivine recovery, possibly lessening the shock stage to the prevalent S1-S2

563 levels found. To account for the microcracks, it is likely that Spade was shocked again after 564 annealing, which would have increased the porosity. That is, shocked, brought to low (e.g., <3\%)

565 porosity, annealed, and then shocked again introducing microcracks that raised the porosity to 566 the level observed (6.6\%). The second shock need not have been strong, but it could have 567 introduced the more highly shocked (S4) material we found. Alternatively, the S4 material is 568 what remains of grains that escaped significant recovery.

569 4.3.9. Queen's Mercy

570 The H6 chondrite Queen's Mercy has a shock stage of S3 (almost S4) but is highly 571 heterogeneous, with olivine grain shock stages almost evenly distributed between S1 and S4 
572 (Fig. 2€). This heterogeneity occurs on a very local scale, sometimes with different grains in the

573 same relict chondrule varying in shock stage (e.g., between S1 and S4). This suggests spatially

574 heterogeneous response to shock. The meteorite has coarse metal veins that grade into thinner

575 troilite and silicate melt veins, making it clear that the coarse metal veins were produced by

576 shock mobilization. With a porosity of only 2.5\%, Queen's Mercy falls into a region of samples

577 with atypically low porosity for an S3 shock stage (Fig. 5). When the porosity and foliation

578 strength factor are considered together, Queen's Mercy is on the borderline of being a low-SPF

579 chondrite (Fig. 6). We propose that Queen's Mercy was shocked to attain metal and other melt

580 veins, foliated metal, and low porosity. High foliation and low porosity together could have been

581 enhanced if a projectile collided a warm parent body target. However, there is no evidence for

582 annealing following impact, so the meteorite source area may not have been deeply buried

583 following impact. An ancient ${ }^{40} \mathrm{Ar} /{ }^{39} \mathrm{Ar}$ age of $4490 \pm 30 \mathrm{Ma}$ (Turner et al., 1978) suggests an

584 early impact, but possibly the meteorite source area was excavated to a near-surface region of the

585 parent body where cooling was relatively rapid.

586 4.3.10 Saint-Séverin

587 Saint-Séverin (LL6) is a breccia containing closely-spaced clasts enclosed in finer588 grained material. We included this meteorite in our sample suite because Ashworth et al. (1977) 589 interpreted incipient recovery of dislocations in olivine grains as indicating shock during slow 590 cooling from high temperatures. Leroux et al. (1996) also examined microstructures in the 591 meteorite and found evidence for an additional later and mild shock event occurring at low 592 temperatures. Hohenberg et al. (1981) found two ${ }^{40} \mathrm{Ar} /{ }^{39} \mathrm{Ar}$ ages for different components of the 593 meteorite, $4420 \pm 10 \mathrm{Ma}$ for dark and $4383 \pm 10 \mathrm{Ma}$ for light lithologies. 
Our observations for Saint-Séverin indicate an unusually large range in olivine shock

595 stages, including the full spectrum ranging from S1-S6 but dominated by olivine grains showing 596 S2 (21\%), S3 (22\%), and S4 (34\%) characteristics (Fig. 2m). There are systematic differences 597 between three thin sections studied, with one section (USNM 2608-2) containing mainly S1-S3 598 material, and two others (CML 0665-1 and -2B) containing mainly S3-S4 material. The weighted 599 shock stage is $3.25(\mathrm{~N}=247$, Table 1), much higher than the $\mathrm{S} 2$ shock stage assigned by Rubin 600 (2004). Porosity and metal foliation strength values are intermediate (Fig. 6). Porosity is typical 601 of S2-S3 chondrites but also similar to that of S4 Leedey (Fig. 5), in rough agreement with the 602 dominant S2-S4 shock stages for olivine. However, the foliation strength better matches that of 603 an S2 chondrite (Fig. 4a).

604 Taken together, these data are consistent with the idea of multiple shock events for Saint605 Séverin. During these events, material that was plastically deformed to differing extents (mainly 606 S2-S4) was intimately mixed. The last significant impact probably was a weak (S2) shock event, 607 possibly at $4383 \mathrm{Ma}$ ago, which established the overall metal foliation. A late weak shock is 608 consistent with the interpretation of Leroux et al. (1996), but the data also can be reconciled with 609 that of Ashworth et al. (1977), if the shock and annealing effects observed by the latter authors 610 pertain to an earlier shock event. Our data place limits on the cumulative effects of these early 611 shock events. They could not have been much more intense than S3-S4 without reducing the 612 porosity to below the observed value, unless porosity was increased by subsequent shocks, for 613 which there is minimal evidence. Further, annealing could not have been so extensive so as to 614 anneal olivine deformation to below the commonly observed S2-S4 levels.

615 Available data for Saint-Séverin can be reconciled with the following complex collisional 616 history. 1) An early strong (S3-S4) shock event, possibly at 4420 Ma ago, produced compacted 
617 and deformed S3-S4 materials with limited (but possibly some) post-shock annealing. 2)

618 Brecciation mixed materials of different shock stages and largely destroyed the metal fabric

619 produced earlier. 3) A later weak (S2) shock, possibly at $4380 \mathrm{Ma}$ ago, produced weakly

620 deformed (S2) olivine, re-established a metal foliation, and re-lithified the meteorite.

\section{4.4. Brecciation and Multiple Impacts}

622 Some chondrites we examined contain heterogeneously deformed olivine (Queen's

623 Mercy, Holbrook, Spade, Saint-Séverin, to a lesser extent Butsura and MIL 99301). This

624 heterogeneity could be caused by inhomogeneous deformation as a result of localized pressure-

625 temperature excursions during shock wave passage in non-uniform rocks (Sharp and DeCarli,

626 2006; Bland et al., 2014), or it could be the result of brecciation, which mixed grains that were

627 deformed in different shock events.

628 We suggest that both inhomogeneous deformation and brecciation were important. The

629 extreme spatial variability of olivine deformation in the same lithic features in Queen's Mercy is

630 best explained by local pressure excursions. Pressure-temperature excursions should be larger for

631 more porous chondrites (Bland et al., 2014). However, among the meteorites in this study there

632 is no obvious correlation between shock heterogeneity and porosity (Table 1), and there is no

633 evidence that variations in porosity contributed to inhomogeneous deformation. Still, we cannot

634 rule out a significant role for inhomogeneous deformation for various chondrites.

635 Brecciation seems likely for both Saint-Séverin and Spade, the former because the

636 meteorite shows obvious clasts, and the latter because the meteorite has a bimodal distribution of

637 olivine grain shock stages (Fig. 2n). Given that all of the chondrites we examined are highly

638 metamorphosed (type 6) chondrites that have relatively uniform grain sizes and textures, which 
639 should minimize local variations in shock pressure, we suggest that most of the meteorites with

640 heterogeneously deformed olivine are in fact breccias.

641 As previously discussed in Sec. 4.1, one would expect multiple shock events to have the

642 effect of decreasing porosity. Conceivably there could be a mismatch between porosity and

643 foliation, and between porosity and shock stage, as porosity reduction should be cumulative

644 during repeated impact, but metal foliation and shock stage should be recording the latest strong

645 shock (Friedrich et al., 2014). It therefore might be possible for a chondrite subjected to multiple

646 impacts to become less porous than expected for a given metal foliation or shock stage.

647 Candidates for such a history of repeated shocks include Portales Valley, GRO 85209, Kernouvé,

648 Estacado, Queen's Mercy, and Morrow County, all of which have low porosity for a given shock

649 stage and metal foliation strength (Fig. 5, 6). However, except for Queen's Mercy, these

650 chondrites do not show evidence for large dispersions in olivine shock stages that one might

651 expect for repeated impacts (Fig. 2).

652 Similarly, chondrites with younger ${ }^{40} \mathrm{Ar} /{ }^{39} \mathrm{Ar}$ ages that likely experienced a long impact

653 history do not necessarily show large dispersions in olivine grain shock stages. Good examples

654 are Leedey, Bruderheim, Alfianello, and Morrow County, which have relatively recent ${ }^{40} \mathrm{Ar} /{ }^{39} \mathrm{Ar}$

655 ages ( 460-3800 Ma, Table 1) and unimodal shock stage distributions (Fig. 2). Despite likely

656 long impact histories, the shock stages, porosities, and metal foliations of these chondrites are all

657 consistent with having been established by the last strong shock. That is, they fit the "simple

658 model" (Fig. 1). This implies that later strong shocks "reset" the characteristics (shock stage,

659 porosity, metal fabric) of the rocks, without any obvious regard to earlier impact history.

660 If later strong shocks reset shock stages and metal foliations, what is the effect of later 661 weak shocks? As shown by Friedrich et al. (2014b), a significantly weaker late shock is not 
662 capable of reorienting metal grains. Similarly, one would not expect overall shock stages to be

663 re-set by a later weak shock: there is no way for plastic deformation of olivine to decrease with

664 subsequent impacts, assuming an absence of significant heating effects during and after shock.

665 Thus, it would appear that only in situations in which an impact breaks apart more deformed

666 material and incorporates less deformed material can the imprints of a later shock potentially be

667 recorded by metal foliation and the shock stages of some grains. That is, a late weak shock event

668 that involves brecciation can potentially destroy an earlier fabric and imprint a new one, and

669 cause an admixture of less deformed olivine grains. The best example of this could be Saint-

670 Séverin (Sec. 4.3.10).

671 4.5. Impacts, Metamorphism, and Parent Body Structures

672 There is little consensus on the role played by collisions during thermal metamorphism of

673 chondrite parent bodies. In one extreme, collisions either did not occur or were relatively

674 insignificant during endogenic heating, resulting in an undisturbed onion-shell structure with

675 metamorphic grade (petrographic types) increasing towards the parent body center (Trieloff et

676 al., 2003; Kleine et al., 2008). In the other extreme, impacts thoroughly disrupted parent bodies

677 during internal heating, causing an extensive scrambling of metamorphic grades in a re-accreted

678 body and leading to a warm rubble pile (Grimm, 1985; Taylor et al., 1987; Ganguly et al., 2013;

679 Scott et al., 2014). It is also possible that localized impact cratering occurred without large-scale

680 disruption of the overall onion shell structure (Harrison and Grimm, 2010). These early impact

681 processes can be distinguished from later events when the parent bodies were cold. For example,

682 it is widely believed that the L-chondrite parent body was significantly disrupted $\sim 470$ Ma ago

683 (e.g., Swindle et al., 2014 and references therein), which could have resulted in the shock effects

684 recorded by such meteorites as Bruderheim and Morrow County. 
Results here support the idea that impacts occurred during thermal metamorphism on all

686 three ordinary chondrite asteroidal bodies. Low-SPF chondrites in this study with Ar age

687 determinations all have old ( 4460-4530 Ma) ages, although MIL 99301 also shows evidence for

688 a younger disturbance (Table 1). These older ages correspond to the approximate time of thermal

689 metamorphism for ordinary chondrites (e.g., Swindle et al., 2014). Conversely, non-low-SPF

690 chondrites in this study all have younger ages ( 460-4400 Ma), although Saint-Séverin also has

691 evidence for an older event (Table 1). Thus, the data suggest that among the meteorites in this

692 study, low-SPF chondrites were affected by early shock events while thermal metamorphism was

693 occurring and the parent bodies were warm, and non-low-SPF chondrites were affected by later

694 shock events while the parent bodies were cold. However, this does not rule out the existence of

695 other non-low-SPF chondrites that were never shocked significantly. Candidates for such

696 chondrites are those with low shock stage and foliations and high porosities, which were not part

697 of this study.

The data provide reasons to be cautious in constructing parent body models. For example,

699 chronology and cooling data for two H6 chondrites we studied, Kernouvé and Estacado, have

700 been used to evaluate onion shell cooling models for the $\mathrm{H}$ chondrite parent body (Trieloff et al.,

701 2003; Kleine et al., 2008; Harrison and Grimm, 2010; Scott et al., 2014). The low (S1) shock

702 stage of these meteorites has been used as evidence for minimal impact disturbance (Trieloff et

703 al., 2003), but both meteorites show evidence for annealing effects that could have reduced their

704 shock stage, and both meteorites have low porosity values that suggest they were affected by one

705 or more impacts. Estacado also shows appreciable metal foliation suggesting impact

706 deformation. Caution should therefore be used when assuming these meteorites were unaffected

707 by shock. TEM observations of Kernouvé suggest that it was never significantly shocked, but 
708 that it was mildly deformed at high temperature and cooled slowly afterwards (Ruzicka et al.,

709 2015a). This implies that for at least this meteorite, impact during metamorphic heating may not

710 have disturbed the overall cooling setting.

711 As with optical deformation of olivine, physical properties including metal foliation and

712 porosity may not be simple to interpret. Metal shape preferred orientation may not faithfully

713 record shock compaction if annealing can destroy fabrics. Porosity is likely to decrease with

714 impacts, but how much will depend on the impact history (single or multiple impacts) and nature

715 of the target (warm, cool). Porosity also can be increased by impacts if the target is relatively

716 non-porous and cool; however the porosity would be in the form of intragranular microcracks.

717 TEM data can provide important details about pre- and post-shock conditions, and the

718 extent of annealing, but are limited in spatial extent (possibly not representative for the meteorite

719 overall if effects are spatially uneven), and can be time consuming to obtain. Cooling rate and

720 chronological approaches are also available, but can be complicated to interpret if heating and

721 cooling history were complex.

722 Thus, there is no single measurement that one can obtain that can fully constrain the

723 interior structures of the $\mathrm{H}, \mathrm{L}$, and LL chondrite parent bodies during metamorphic heating.

724 Multiple data types for the same meteorites, and multiple meteorites of different types, together

725 with modelling, seem the most promising way to evaluate the relative importance and interplay

726 between impacts and metamorphic heating.

\section{CONCLUSIONS}

728 There are two good explanations for apparently weakly shocked, low-porosity, and

729 weakly foliated (low-SPF) chondrites: 1) post-shock annealing obliterated olivine strain and/or

730 metal foliation in these meteorites, and 2) shock occurred under warm conditions different from 
731 other chondrites, which allowed more reduction of porosity. Both explanations may be correct.

732 Annealing and recovery could have obliterated strain and caused a reduction in shock stage

733 (Rubin, 2004; Ruzicka et al., 2015a), and elevated temperatures would have permitted additional

734 compaction during deformation (Hirata et al., 2008; Nakamura et al., 2000). These features can

735 be explained by the formation of annealed chondrites at depth directly below an impact crater on

736 an already warm parent body. Transport to deeper or shallower portions and to different cooling

737 environments of warm bodies could have occurred. Relying on shock stage alone, as determined

738 by observations of petrographic thin section, for cooling and shock history models of ordinary

739 chondrites may be inadequate. More broadly, it appears that portions of the parent bodies of the

$740 \mathrm{H}, \mathrm{L}$, and LL chondrites were initially deformed and compacted while these bodies were

741 undergoing thermal metamorphism. Shock compaction under warm conditions may have been an

742 important accretionary process and likely helped lithify the planetesimals.

\section{ACKNOWLEDGMENTS}

745 This study was supported by NASA grant NNX10AH336 (Origins program, PI AR, Co-I JF). 746 Portions of this work were performed at GeoSoilEnviroCARS (Sector 13), Advanced Photon 747 Source (APS), Argonne National Laboratory. GeoSoilEnviroCARS is supported by the National 748 Science Foundation - Earth Sciences (EAR-1128799) and Department of Energy- GeoSciences 749 (DE-FG02-94ER14466). This research used resources of the Advanced Photon Source, a U.S. 750 Department of Energy (DOE) Office of Science User Facility operated for the DOE Office of 751 Science by Argonne National Laboratory under Contract No. DE-AC02-06CH11357. 


\section{REFERENCES}

754 Ashworth J. R. (1981) Fine structure in H-group chondrites. Proc. Royal Soc. Lond. A 374, 179755194.

756

757

758

759

760

761

762

763

764

765

766

767

768

769

770

771

772

773

774

775

776

777

778

779

780

781

782

783

784

785

786

787

788

789

790

791

792

793

794

795
Ashworth J. R., Barber D. J., Brown G. M., Smith J. V. (1977) Electron Microscopy of Some Stony Meteorites [and Discussion]. Phil. Trans. Royal Soc. Lond. A 286, 493-506.

Bland P.A., Collins G.S., Davison T.M., Abreu N.M., Ciesla F.J., Muxworthy A.R. and Moore J. (2014) Pressure-temperature evolution of primordial solar system solids during impact-induced compaction. Nature Communications 5, 541, DOI: 10.1038.

Bogard D., Hortz F., Johnson P. (1987) Shock effects and argon loss in samples of the Leedey L6 chondrite experimentally shocked to 29-70 GPa pressures. Geochim. Cosmochim. Acta Acta, 51, 2035-2044.

Cain P. M., McSween H.Y., Woodward N. B. (1986) Structural deformation of the Leoville chondrite. Earth Planet. Sci. Lett. 77, 165-175.

Consolmagno, G. J., Macke, R. J., Rochette, P., Britt, D. T., \& Gattacceca, J. (2006) Density, magnetic susceptibility, and the characterization of ordinary chondrite falls and showers. Meteorit. Planet. Sci. 41, 331-342.

Consolmagno G. J., Britt D. T. and Macke R. J. (2008) The significance of meteorite density and porosity. Chemie der Erde 68, 1-29.

Dixon E.T., Bogard D.D., Garrison D.H. and Rubin A.E. (2004) ${ }^{39} \mathrm{Ar}-{ }^{40} \mathrm{Ar}$ evidence for early impact events on the LL parent body. Geochim. Cosmochim. Acta 68, 3779-3790.

Dyl K. A., Benedix G K., Bland, P. A., Friedrich J. M., Spurný P., Towner M. C., O’Keefe M,C., Howard K., Greenwood R., Macke R. J., Britt D. T., Halfpenny A., Thostenson J. O., Rudolph R. A., Rivers M. L., Bevan A. W. R. (2016) Characterization of Mason Gully (H5): The Second Recovered Fall from the Desert Fireball Network. Meteorit. Planet. Sci. 51, 596-613. doi: 10.1111/maps.12605

Friedrich J. M., Wignarajah D. P., Chaudhary S., Rivers M. L., Nehru C. E., Ebel D. S. (2008a) Three-dimensional petrography of metal phases in equilibrated L chondrites-Effects of shock loading and dynamic compaction. Earth Planet. Sci. Lett. 275, 172-180. doi:10.1016/j.epsl.2008.08.024

Friedrich J. M., Macke R. J., Wignarajah D. P., Rivers M. L., Britt D. T., Ebel D. S. (2008b) Pore size distribution in an uncompacted equilibrated ordinary chondrite. Planet. Space Sci. 56, 895-900. doi:10.1016/j.pss.2008.02.002 
Friedrich J. M. and Rivers M. L. (2013) Three-dimensional imaging of ordinary chondrite microporosity at 2.6 micrometer resolution. Geochim. Cosmochim. Acta 116, 63-70. doi: 10.1016/j.gca.2011.08.045

Friedrich J. M., Ruzicka A., Rivers M. L., Ebel D. S., Thostenson J. O., Rudolph R. A. (2013) Metal veins in the Kernouvé (H6 S1) chondrite: Evidence for pre- or syn-metamorphic shear deformation. Geochim. Cosmochim. Acta 116, 71-83. doi: 10.1016/j.gca.2013.01.009

Friedrich J. M., Rubin A. E., Beard S. P., Swindle T. D., Isachsen C. E., Rivers M. L., Macke R. J. (2014a) Ancient porosity preserved in ordinary chondrites: examining shock and compaction on young asteroids. Meteorit. Planet. Sci. 49, 1214-1231. doi: 10.1111/maps.12328

Friedrich J. M., Weisberg M. K., Rivers M. L. (2014b) Multiple impact events recorded in the NWA $7298 \mathrm{H}$ chondrite breccia and the dynamical evolution of an ordinary chondrite asteroid. Earth Planet. Sci. Lett. 394, 13-19. doi: 10.1016/j.epsl.2014.03.016

Ganguly J., Massimiliano T., Sumit C., Kenneth D. (2013) H-chondrite parent asteroid: A multistage cooling, fragmentation and re-accretion history constrained by thermometric studies, diffusion kinetic modeling and geochronological data. Geochim. Cosmochim. Acta 105, 206-220.

Garrison D.H. and Bogard D.D. (2001) ${ }^{39} \mathrm{Ar}-{ }^{40} \mathrm{Ar}$ and space exposure ages of the unique Portales Valley H-chondrite. Lunar Planet. Sci. Conf. 32, abstr. 1137.

Gattacceca, J., Rochette, P., Denise, M., Consolmagno, G., Folco, L. (2005) An impact origin for the foliation of chondrites. Earth Planet. Sci. Lett. 34, 351-368.

Geiss J. and Hess D.C. (1958) Argon-potassium ages and the isotoipic composition of argon from meteorites. Astrophys. J. 127, 224-236.

Grimm R.E. (1985) Penecontemporaneous metamorphism, fragmentation, and reassembly of ordinary chondrite parent bodies. J. Geophys. Res. 90, 2022-2028.

Guignard J. and Toplis M.J. (2015) Textural properties of iron-rich phases in H ordinary chondrites and quantitative links to the degree of thermal metamorphism. Geochim. Cosmochim. Acta 149, 45-63.

Harrison K. and Grimm R.E. (2010) Thermal constraints on the early history of the H-chondrite parent body reconsidered. Geochim. Cosmochim. Acta 74, 5410-5423.

Henke S., Gail H.-P., Trieloff M., Schwarz W. H., and Kleine T. (2012) Thermal evolution and sintering of chondritic planetesimals. Astro. \& Astrophys. 537:A45.

Hirata N., Kurita K., Sekine T. (2008) Simulation experiments for shocked primitive materials in the Solar System. Phys. Earth Planet. Int. 174, 227-241. 
Hohenberg C.M., Hudon B., Kennedy B.M., and Podosek F.A. (1981) Noble gas retention chronologies for the St. Severin meteorite. Geochim. Cosmochim. Acta 45, 535-540.

Hutchison R. (2004) Meteorites: A Petrologic, Chemical and Isotopic Synthesis. Cambridge University Press, Cambridge.

Jamsja N. and Ruzicka A. (2010) Shock and thermal history of Northwest Africa 4859, an annealed impact melt breccia of LL chondrite parentage containing unusual igneous features and pentlandite. Meteorit. Planet. Sci. 45, 828-849.

Jenniskens P., Rubin A. E., Yin Q.-Z., Sears D. W. G., Sandford S. A., Zolensky M. E., Krot A. N., Blair L., Kane D., Utas J., Verish R., Friedrich J. M., Wimpenny J., Eppich G. R., Ziegler K., Verosub K. L., Rowland D. J., Albers J., Gural P. S., Grigsby B., Fries M. D., Matson R., Johnston M., Silber E., Brown P., Yamakawa A., Sanborn M. E., Laubenstein M., Welton K. C., Nishiizumi K., Meier M. M. M., Busemann H., Clay P., Schmitt-Kopplin Ph., Glavin D. P., Callahan M. P., Dworkin J. P., Wu Q., Zare R. N., Grady M., Verchovsky S., Emel'yanko V., Naroenkov S., Clark D., Girten B., Worden P. S. (2014) Fall, Recovery, and Characterization of the Novato L6 chondrite breccia. Meteorit. Planet. Sci. 49, 1388-1425. doi: 10.1111/maps.12323

Kleine T., Touboul M., Van Orman J.A., Bourdon B., Maden C., Mezger K. and Halliday A.N. (2008) Hf-W thermochronometry: closure temperature and constraints on the accretion and cooling history of the H chondrite parent body. Earth Planet. Sci. Lett. 270, 106-118.

Kohout T., Gritsevich M., Grokhovsky V. I., Yakovlev G. A., Haloda J., Halodova P., Michallik R., M., Penttilä A., Muinonen K. (2014) Mineralogy, reflectance spectra, and physical properties of the Chelyabinsk LL5 chondrite - Insight into shock-induced changes in asteroid regoliths. Icarus 228, 78-85.

Kring D. A., Hill D. H., Gleason J. D., Britt D. T., Consolmagno G. J., Farmer M., Wilson S., Haag R. (1999) Portales Valley: A meteoritic sample of the brecciated and metal-veined floor of an impact crater on an H-chondrite asteroid. Meteorit. Planet. Sci. 34, 663-669.

Kunz, J., Falter, M. and Jessberger, E. K. (1997) Shocked meteorites: argon-40-argon-39 evidence for multiple impacts. Meteorit. Planet. Sci. 32, 647-670.

Leroux H., Doukhan J.-C., Guyot F. (1996) An analytical electron microscopy (AEM) investigation of opaque inclusions in some type 6 ordinary chondrites. Meteorit. Planet. Sci. 31, 767-776.

Macke R. J. (2010) Survey of meteorite physical properties: density, porosity, and magnetic susceptibility. Ph. D. thesis, University of Central Florida.

Macke R. J., Kent J. J., Kiefer W. S. and Britt D. T. (2015) 3D-Laser-Scanning Technique Applied to Bulk Density Measurements of Apollo Lunar Samples. $46^{\text {th }}$ Lunar and Planetary Science Conference (abstract \#1716). 
Nakamura, T., Tomeoka, K., Sekine, T. and Takeda, H. (1995) Impact-induced chondrule flattening in the Allende CV3 carbonaceous chondrite: shock experiments. Meteoritics 30, 344347.

Nakamura, T., Tomeoka, K., Takaoka, N., Sekine, T. and Takeda, H. (2000) Impact-induced textural changes of CV carbonaceous chondrites: experimental reproduction. Icarus 146, 289300.

Popova O. P., Jenniskens P., Emel'yanenko V., Kartashova A., Biryukov E., Khaibrakhmanov S., Shuvalov V., Rybnov Y., Dudorov A., Grokhovsky V. I., Badyukov D. D., Yin Q.-Z., Gural P. S., Albers J., Granvik M., Evers L. G., Kuiper J., Kharlamov V., Solovyov A., Rusakov Y. S., Korotkiy S., Serdyuk I., Korochantsev A. V., Larionov M. Yu., Glazachev D., Mayer A. E., Gisler G., Gladkovsky S. V., Wimpenny J., Sanborn M. E., Yamakawa A., Verosub K. L., Rowland D. J., Roeske S., Botto N. W., Friedrich J. M., Zolensky M. E., Le L., Ross D., Ziegler K., Nakamura T., Ahn I., Lee J. I., Zhou Q., Li Z.-H., Li Q.-L., Liu Y., Tang G.-Q., Hiroi T., Sears D., Weinstein I. A., Vokhmintsev A. S., Ishchenko A. V., Schmitt-Kopplin P., Hertkorn N., Nagao K., Haba M. K., Komatsu M., Mikouchi T. (2013) Chelyabinsk Airburst, Damage Assessment, Meteorite Recovery and Characterization. Science 234, 1069-1073. doi: $10.1126 /$ science. 1242642

Rubin A. E. (2002) Post-shock annealing of Miller Range 99301 (LL6): Implications for impact heating of ordinary chondrites. Geochim. Cosmochim. Acta 66, 327-3337.

Rubin A. E. (2004) Postshock annealing and postannealing shock in equilibrated ordinary chondrites: Implications for the thermal and shock histories of chondritic asteroids. Geochim. Cosmochim. Acta 68, 673-689.

Rubin A. E., Jones R. H. (2003) Spade: An H chondrite impact-melt breccia that experienced post-shock annealing. Meteorit. Planet. Sci. 38, 1507-1520.

Ruzicka, A., Killgore, M., Mittlefehldt, D.W. and Fries, M.D. (2005) Portales Valley: Petrology of a metallic melt meteorite breccia. Meteorit. Planet. Sci. 40, 261-295.

Ruzicka A., Hugo R. and Hutson M. (2015a) Deformation and thermal histories of ordinary chondrites: Evidence for post-deformation annealing and syn-metamorphic shock. Geochim. Cosmochim. Acta 163, 219-233.

Ruzicka A.M., Clay P.M., Hugo R., Joy K.H. and Busemann H. (2015b) Contrasting early and late shock effects on the $\mathrm{L}$ chondrite parent body: Evidence from Ar ages and olivine microstructures for two meteorites. Meteorit. Planet. Sci., Abstract \#5177.

Sasso M. R., Macke R. J., Boesenberg J. S., Britt D. T., Rivers M. L., Ebel D. S., Friedrich J. M. (2009) Incompletely compacted equilibrated ordinary chondrites. Meteorit. Planet. Sci. 44, 1743 1753. doi:10.1111/j.1945-5100.2009.tb01204.x

Schmitt R.T. (2000) Shock experiments with the H6 chondrite Kernouve: Pressure calibration of 
933

934

935

936

937

938

939

940

941

942

943

944

945

946

947

948

949

950

951

952

953

954

955

956

957

958

959

960

961

962

963

964

965

966

967

968

969

970

971

972

973

974

microscopic shock effects. Meteorit. Planet. Sci. 35, 545-560.

Scott E. R. D., Krot T. V., Goldstein J. I., Wakita S. (2014) Thermal and impact history of the H chondrite parent asteroid during metamorphism: Constraints from metallic Fe-Ni. Geochim. Cosmochim. Acta 136, 13-37.

Sharp T. G., and DeCarli P. S. (2006) Shock Effects in Meteorites. In Meteorites and the Early Solar System II (eds. D. S. Lauretta and H. Y. McSween Jr.). University of Arizona Press, Tucson. pp.653-677.

Sneyd D. S., McSween H. Y. Jr., Sugiura N., Strangway D. W., and Nord G. L. Jr. (1988) Origin of petrofabrics and magnetic anisotropy in ordinary chondrites. Meteoritics 23, 139-149.

Stöffler D., Keil K., and Scott E. R. D. (1991) Shock metamorphism of ordinary chondrites. Geochim. Cosmochim. Acta 55, 3845-3867.

Swindle T. D., Kring D.A. and Weirich J.R. (2014) ${ }^{40} \mathrm{Ar} /{ }^{39} \mathrm{Ar}$ ages of impacts involving ordinary chondrite meteorites. Geological Society, London, Special Publications 378, 333-347.

Taylor G. J., Maggiore P. Scott E. R. D., Rubin A.E., Keil K. (1987) Original structures, and fragmentation and reassembly histories of asteroids - Evidence from meteorites. Icarus 69, 1-13.

Trieloff M., Jessberger E.K., Herrwerth I., Hopp J., Fiéni C., Ghélis M., Bourot-Denise M. and Pellas P. (2003) Structure and thermal history of the H-chondrite parent asteroid revealed by thermochronometry. Earth Planet. Sci. Lett. 190, 267-269.

Turner G. (1969) Thermal histories of meteorites by the ${ }^{39} \mathrm{Ar}-{ }^{40} \mathrm{Ar}$ method. In: Millman, P. (ed.) Meteorite Research. D. Reidel, Dordrecht, 407-417.

Turner, G., Miller, J. A. and Grasty, R. L. (1966) The thermal history of the Bruderheim meteorite. Earth Planet. Sci. Lett. 1, 155-157.

Turner G., Enright M.C. and Cadogan P.H. (1978) The early history of chondrite parent bodies inferred from ${ }^{40} \mathrm{Ar}-{ }^{39} \mathrm{Ar}$ ages. Proc. Lunar Planet. Sci. Conf. 9th, 989-1025.

Woodcock N. H. (1977) Specification of fabric shapes using an eigenvalue method. Geo. Soc. Am. Bull. 88, 1231-1236.

Woodcock N. H. and Naylor M. A. (1983) Randomness testing in three-dimensional orientation data. J. Struct. Geo. 5, 539-548. 
976 Table 1. Sample list, with physical, petrographic and age data.

\begin{tabular}{|c|c|c|c|c|c|c|c|c|}
\hline meteorite & symbol & $\begin{array}{c}\text { group } \\
\& \\
\text { type }\end{array}$ & $\begin{array}{l}\text { shock } \\
\text { stage }^{1}\end{array}$ & $\begin{array}{l}\text { weighted shock } \\
\text { stage }^{2}\end{array}$ & $\begin{array}{c}\text { subgrain } \\
\text { boundaries }^{3}\end{array}$ & $\begin{array}{l}\text { foliation } \\
\text { strength } \\
\text { factor } \\
\text { (C) }\end{array}$ & $\begin{array}{l}\text { porosity } \\
(\%)^{4}\end{array}$ & $\begin{array}{l}\text { Ar age } \\
(\mathrm{Ma})^{5}\end{array}$ \\
\hline Alfianello & Alf & L6 & S5 & $4.18 \pm 0.56(131)$ & & 1.13 & 8.7 & $1050 \pm 60$ \\
\hline Bruderheim & Brd & L6 & S4 & $3.78 \pm 0.66(136)$ & & 0.56 & 5.7 & $465 \pm 30$ \\
\hline Butsura & But & H6 & $\mathrm{S} 1^{*}$ & $1.63 \pm 1.00(54)$ & & 0.23 & $6.6 \pm 2.0$ & $4480 \pm 30$ \\
\hline Estacado & Est & H6 & S1 & $1.26 \pm 0.74$ & yes & 0.40 & 4.3 & $4435 \pm 5$ \\
\hline GRO 85209 & GRO & L6 & S1 & n.a. & & 0.03 & $2.2 \pm 0.7$ & \\
\hline Holbrook & Hol & L6 & $\mathrm{S} 3^{*}$ & $2.38 \pm 1.16(144)$ & & 0.65 & 10.4 & $4400 \pm 100$ \\
\hline Kernouvé $^{\dagger}$ & Krn & H6 & S1 & $1.13 \pm 0.55(115)$ & yes & $\begin{array}{l}0.04 \\
0.12\end{array}$ & 5.8 & $4463 \pm 11$ \\
\hline Leedey & Ldy & L6 & S4 & $3.94 \pm 0.54(162)$ & & $\begin{array}{l}0.51 \\
0.66\end{array}$ & 9.1 & $3800 \pm 100$ \\
\hline MIL 99301 & MIL & LL6 & $\mathrm{S} 1^{*}$ & $1.60 \pm 1.30(65)$ & yes & $\begin{array}{l}0.07 \\
0.10\end{array}$ & 10.5 & $\begin{array}{l}4230 \pm 30 \\
4520 \pm 80\end{array}$ \\
\hline Morrow County & $\mathrm{MC}$ & L6 & S5 & $4.46 \pm 0.56(149)$ & & 0.58 & $2.6 \pm 1.6$ & $460 \pm 10$ \\
\hline Park & Prk & L6 & S1 & $1.35 \pm 0.72(153)$ & (yes) & 0.04 & $8.3 \pm 4.7$ & $4526 \pm 5$ \\
\hline Portales Valley\# & PV & $\mathrm{H} 6 / 7$ & S1 & $1.16 \pm 0.37(100)$ & yes & 0.16 & $0.5 \pm 0.2$ & $4477 \pm 16$ \\
\hline Queen's Mercy & $\mathrm{QM}$ & H6 & $\mathrm{S} 3{ }^{*}$ & $2.56 \pm 1.09(57)$ & & 0.65 & $2.5 \pm 0.8$ & $4490 \pm 30$ \\
\hline Saint-Séverin & SS & LL6 & $\mathrm{S} 4^{*}$ & $3.25 \pm 1.23(247)$ & & 0.34 & $9.9 \pm 1.6$ & $\begin{array}{l}4383 \pm 10 \\
4420 \pm 10\end{array}$ \\
\hline Spade & Spa & H6 & $\mathrm{S} 4^{*}$ & $2.39 \pm 1.36(97)$ & yes & 0.30 & $6.6 \pm 2.6$ & \\
\hline Tenham & Ten & L6 & S5 & $4.26 \pm 0.64(169)$ & & 0.80 & $4.4 \pm 0.7$ & \\
\hline
\end{tabular}

${ }^{1}$ Conventional shock stage this study except for Bruderheim, Leedey, MIL 99301, Morrow County, Park, and

979 Portales Valley (Ruzicka et al., 2015a) and Kernouvé (Friedrich et al., 2013b). Asterisks (*) indicate chondrites with inhomogeneous shock effects (see Text and weighted shock stage column).

$981{ }^{2}$ Weighted or mean shock stage ( \pm denotes standard deviation value, value in parentheses give number of grains), using the method of Jamsja and Ruzicka (2010) and Ruzicka et al. (2015a). n.a. = not available.

$983{ }^{3}$ Optically visible subgrain boundaries in otherwise lightly deformed olivine grains. Some subgrains are present in 984 Park but fewer than in other meteorites that have them.

$985 \quad{ }^{4}$ See Text for data sources and discussion of errors.

$986{ }^{5}{ }^{40} \mathrm{Ar}{ }^{39} \mathrm{Ar}$ ages (K-Ar age for Holbrook), data from literature including: Kunz et al. (1997) —Alfianello; Turner et

987 al. (1966) and Turner (1969)—Bruderheim; Trieloff et al. (2003)—Estacado, Kernouvé; Turner et al. (1978)—

988 Butsura, Kernouvé, Queen's Mercy; Geiss and Hess (1958)—Holbrook; Bogard et al. (1987)—Leedey; Dixon et al.

989 (2004)—MIL 99301; Ruzicka et al. (2015b) — Morrow County, Park; Garrison and Bogard (2001) —Portales Valley;

990 Hohenberg et al. (1981) — Saint-Séverin.

991 Kernouvé data reproduced from Friedrich et al. (2013b).

$992 *$ Second Leedey datum from this work, other from Friedrich et al. (2008a).

993 \# Silicate (excluding coarse metal vein) portion only. 
996 Table 2. Compilation of additional data.

\begin{tabular}{|c|c|c|c|c|c|}
\hline meteorite & group \& type & $\begin{array}{c}\text { foliation } \\
\text { strength } \\
\text { factor }(\mathrm{C})\end{array}$ & $\begin{array}{l}\text { shock } \\
\text { stage }\end{array}$ & $\begin{array}{l}\text { porosity } \\
(\%)\end{array}$ & references \\
\hline Akaba & L6 & 0.51 & - & - & Friedrich et al. (2008a) \\
\hline Apt & L6 & 0.69 & S4 & 8.4 & Friedrich et al. (2008a), Macke (2010) \\
\hline Atemajac & L6 & 0.31 & - & - & Friedrich et al. (2008a) \\
\hline Bachmut & L6 & 0.72 & S3 & 6.3 & Friedrich et al. (2008a), Macke (2010) \\
\hline Barratta & L4 & 0.43 & S4 & 5.3 & Friedrich et al. (2008a), Macke (2010) \\
\hline Baszkówka & L5 & $0.20,0.05$ & S1 & 19.0 & $\begin{array}{l}\text { Friedrich et al. (2008a), Friedrich et al. } \\
\text { (2008b), Friedrich et al. (2014a) }\end{array}$ \\
\hline Bath Furnace & L6 & 0.39 & - & 4.6 & this work, Macke (2010) \\
\hline Bjurböle & L/LL4 & $\begin{array}{l}0.31,0.32 \\
0.26,0.29\end{array}$ & S1 & 19.8 & $\begin{array}{l}\text { Friedrich et al. (2008a), Macke (2010), this } \\
\text { work }\end{array}$ \\
\hline Bluff & L5 & 0.68 & S6 & 4.0 & Friedrich et al. (2008a), Macke (2010) \\
\hline Castine & L6 & $0.49,0.44$ & - & - & Friedrich et al. (2008a) \\
\hline Chelyabinsk & LL5 & 1.23 & S4 & 6.0 & Popova et al. (2013), Kohout et al. (2014) \\
\hline De Nova & L6 & 0.52 & S2 & - & Friedrich et al. (2008a) \\
\hline Duruma & L6 & 0.40 & - & - & Friedrich et al. (2008a) \\
\hline Ellerslie & L5 & 0.69 & S4 & - & Friedrich et al. (2008a) \\
\hline Fremont Butte & L4 & 0.68 & S6 & - & Friedrich et al. (2008a) \\
\hline Grant County & L6 & 0.19 & S2 & - & Friedrich et al. (2008a) \\
\hline Harrison County & L6 & 0.40 & S2 & & Friedrich et al. (2008a) \\
\hline Kyushu & L6 & 0.85 & S5 & 5.4 & Friedrich et al. (2008a), Macke (2010) \\
\hline L'Aigle & L6 & 0.40 & S2 & 6.8 & Friedrich et al. (2008a), Macke (2010) \\
\hline Mason Gully & H5 & 0.24 & S2 & 10.8 & Dyl et al. (2016) \\
\hline McKinney & L4 & 0.64 & S6 & 2.8 & Friedrich et al. (2008a), Macke (2010) \\
\hline Middlesbrough & L6 & 0.41 & - & - & Friedrich et al. (2008a) \\
\hline Miller (AR) & H5 & 0.06 & S1 & 20.0 & $\begin{array}{l}\text { Sasso et al. (2009), Friedrich et al. (2014a) } \\
\text { this work }\end{array}$ \\
\hline Moorleah & L6 & 0.46 & S3 & - & Friedrich et al. (2008a) \\
\hline Mount Tazerzait & L5 & 0.07 & S1 & 12.6 & $\begin{array}{l}\text { Sasso et al. (2009), Friedrich et al. (2014a) } \\
\text { this work }\end{array}$ \\
\hline Novato & L6 & $0.96,1.08$ & S4 & - & Jenniskens et al. (2014) \\
\hline NWA 2380 & LL5 & 0.12 & S1 & 18.7 & $\begin{array}{l}\text { Sasso et al. (2009), Friedrich et al. (2014a) } \\
\text { this work }\end{array}$ \\
\hline NWA 7298 (lith. A) & $\mathrm{H} 3.8$ & 0.28 & S2 & - & Friedrich et al. (2014b) \\
\hline NWA 7298 (lith. B) & H3.8 & 0.78 & S3 & - & Friedrich et al. (2014b) \\
\hline NWA 7298 (lith. C) & $\mathrm{H} 3.8$ & 0.19 & S1 & - & Friedrich et al. (2014b) \\
\hline Quenggouk & $\mathrm{H} 4$ & 0.32 & - & 15.1 & this work, Macke (2010) \\
\hline Sahara 98034 & H5 & 0.05 & S1 & 16.1 & $\begin{array}{l}\text { Sasso et al. (2009), Friedrich et al. (2014a) } \\
\text { this work }\end{array}$ \\
\hline Saratov & L4 & $\begin{array}{c}0.32,0.32 \\
0.27,0.27 \\
0.39\end{array}$ & S2 & 13.5 & $\begin{array}{l}\text { Friedrich et al. (2008a), Macke (2010), this } \\
\text { work }\end{array}$ \\
\hline Tennasilm & L4 & $0.33,0.36$ & S3 & 10.7 & Friedrich et al. (2008a), Macke (2010) \\
\hline Tjerebon & L5 & 0.05 & $\mathrm{~S} 1$ & 9.8 & $\begin{array}{l}\text { Sasso et al. (2009), Friedrich et al. (2014a) } \\
\text { this work }\end{array}$ \\
\hline Utrecht & L6 & 0.31 & S3 & - & Friedrich et al. (2008a) \\
\hline
\end{tabular}


1001 Table 3. Grouping of chondrites according to their physical properties and shock stages.

1002 Meteorites with asterisks indicate those in this study, and those in parentheses have borderline

1003 values and less certainly fit within the respective groups.

\begin{tabular}{|c|c|c|c|}
\hline $\begin{array}{l}\text { Chondrites with low } \\
\text { shock stage \& porosity }\end{array}$ & $\begin{array}{l}\text { Chondrites with low } \\
\text { porosity \& metal } \\
\text { foliation }\end{array}$ & $\begin{array}{l}\text { Chondrites with low } \\
\text { shock stage \& porosity \& } \\
\text { metal foliation (low-SPF } \\
\text { group) }\end{array}$ & $\begin{array}{l}\text { Other chondrites } \\
\text { (non-low-SPF group) }\end{array}$ \\
\hline $\begin{array}{l}\text { Butsura* } \\
\text { Estacado* } \\
\text { GRO 85209* } \\
\text { Kernouve* } \\
\text { L'Aigle } \\
\text { (MIL 99301*) } \\
\text { Park* } \\
\text { Portales Valley* } \\
\text { Queen's Mercy* } \\
\text { (Spade*) } \\
\text { Tjerebon }\end{array}$ & $\begin{array}{l}\text { (Barratta) } \\
\text { Bath Furnace } \\
\text { Butsura* } \\
\text { Estacado* } \\
\text { GRO 85209* } \\
\text { Kernouve* } \\
\text { (L'Aigle) } \\
\text { (MIL 99301*) } \\
\text { (Morrow County)* } \\
\text { Park* } \\
\text { Portales Valley* } \\
\text { (Queen's Mercy*) } \\
\text { Spade* } \\
\text { Tjerebon }\end{array}$ & $\begin{array}{l}\text { Bath Furnace? }^{1} \\
\text { Butsura* } \\
\text { Estacado* } \\
\text { GRO 85209* } \\
\text { Kernouve* } \\
\text { (L'Aigle) } \\
\text { (MIL 99301*) } \\
\text { Park* } \\
\text { Portales Valley* } \\
\text { (Queen's Mercy*) } \\
\text { Spade* } \\
\text { Tjerebon }\end{array}$ & $\begin{array}{l}\text { Alfianello* } \\
\text { Bruderheim* } \\
\text { Holbrook* } \\
\text { Leedey* } \\
\text { Morrow County* } \\
\text { Saint-Séverin* } \\
\text { Tenham* } \\
\quad+ \\
31 \text { others (Table 2) }\end{array}$ \\
\hline
\end{tabular}




\section{FIGURE CAPTIONS}

Fig. 1. Schematic diagram showing the expected relationship between shock stage, porosity, and metal grain foliation as a result of shock compaction. For the simple model trend (approximated by solid curve), stronger shocks decrease porosity and increase metal foliation. Increasing shock will reduce intergranular porosity until it is removed, except that additional shock will introduce intragranular microcracks, so porosity will never reach $0 \%$. Even weak shocks might be capable of considerably reducing porosity, so porosity could decrease rapidly at low shock stage for slightly stronger shocks. The dashed vertical arrow represents a path for extra compaction caused by shock-related deformation of material already at elevated temperatures. The dashed horizontal arrow represents a path for apparent decreased foliation caused by grain growth and for lower shock stage by healing of defects during post-shock thermal annealing. These processes can cause chondrites to shift off of the simple model trend for weaker and stronger shocks.

Fig. 2. Shock stage histograms for meteorites in this study based on optical microscopy data for olivine. Conventional shock stages are shown outside brackets, weighted shock stages given in brackets, and percentages of grains with different characteristics are given above bars. $\mathrm{N}=$ number of olivine grains. Values for grain percentages and weighted shock stages have been rounded. Queen's Mercy (part 1) is designated as S3 based on non-rounded values.

Fig. 3. Equal area stereographic projections (lower hemisphere) for metal grain shape orientations (long axes of metal grains) based on microtomography data for representative chondrites with different orientation strength factors, C. Individual grain data are at left and contoured data (red $=$ higher concentrations, blue $=$ lower concentrations of poles) at right. $\mathrm{n}=$ number of grains. The web version of this figure is in color.

Fig. 4. Relationship between degree of preferred shape orientation of metal (embodied in the parameter $\mathrm{C}$, foliation strength) and (a) conventional and (b) weighted shock stage. In cases where multiple $\mathrm{C}$ values were determined, an average is shown (except for the three lithologies for NWA 7298). Representative errors are based on an average of the standard deviation of C values (this study and literature) and an average of the standard deviation of weighted shock stage values (this study) for a given meteorite, with bar lengths $=1$ standard deviation. Meteorite symbols are as in Table 1 and also: $\mathrm{Tj}=$ Tjerebon, $\mathrm{LA}=\mathrm{L}$ 'Aigle, and $\mathrm{Ba}=$ Barratta. Meteorites in this study are coded based on whether they are low-SPF (low shock-porosity-foliation) chondrites or not; see Text. The web version of this figure is in color.

Fig. 5. Relationship between bulk porosity and (a) conventional and (b) weighted shock stage. In cases where multiple porosity values were determined, an average is shown. Representative errors are based on an average of the standard deviation of porosity values and an average of the standard deviation of weighted shock stage values for a given meteorite, with bar lengths $=1$ 
1046 standard deviation, utilizing data from this study. Meteorite symbols and designations are as in 1047 Table 1 and Fig. 4. The dashed line is a guideline dividing meteorites with low porosities and 1048 shock stages (below line) from others. The web version of this figure is in color.

1049

1050 Fig. 6. Relationship between porosity and preferred shape orientation of metal grains (embodied 1051 in $\mathrm{C}$, foliation strength). The dashed line is a guideline dividing meteorites with low porosities 1052 and foliations (below line) from others. Symbols, data, and abbreviations as described in Fig. 4 1053 and 5, together with: BF = Bath Furnace. The web version of this figure is in color.

1054

1055 
1057 Fig. 1.

1058

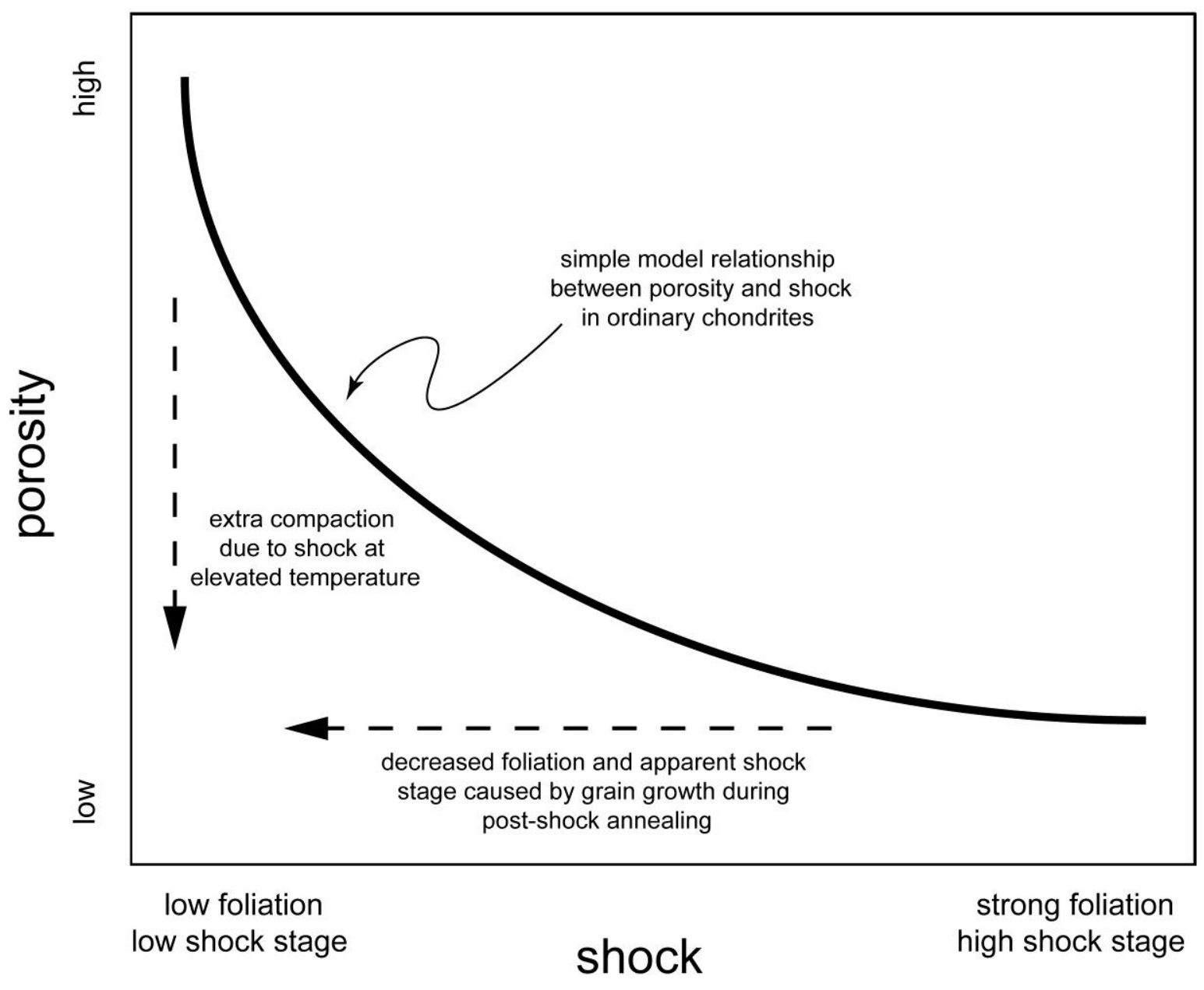

1059 
1061

1062 Fig. 2.

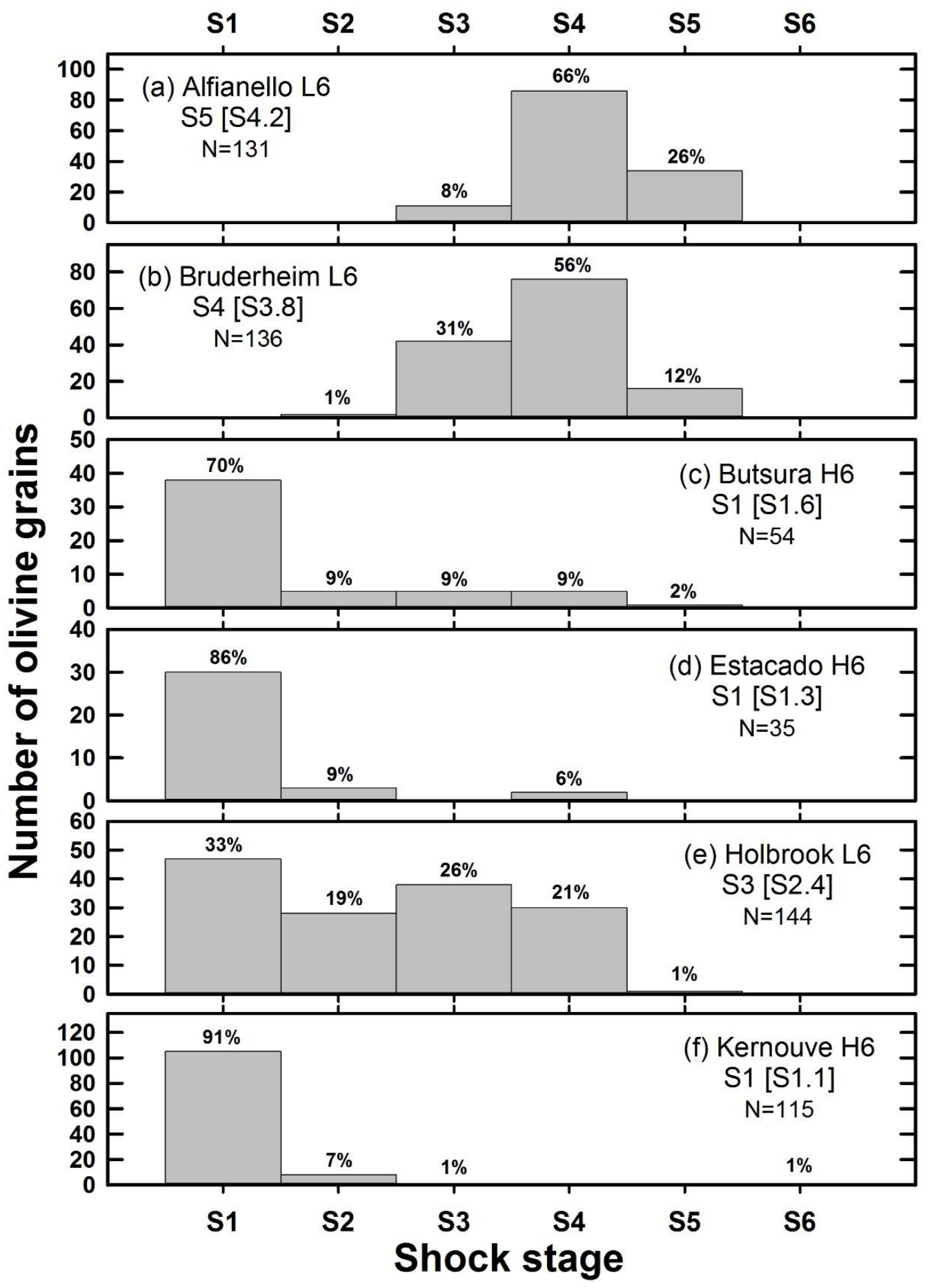

1064 


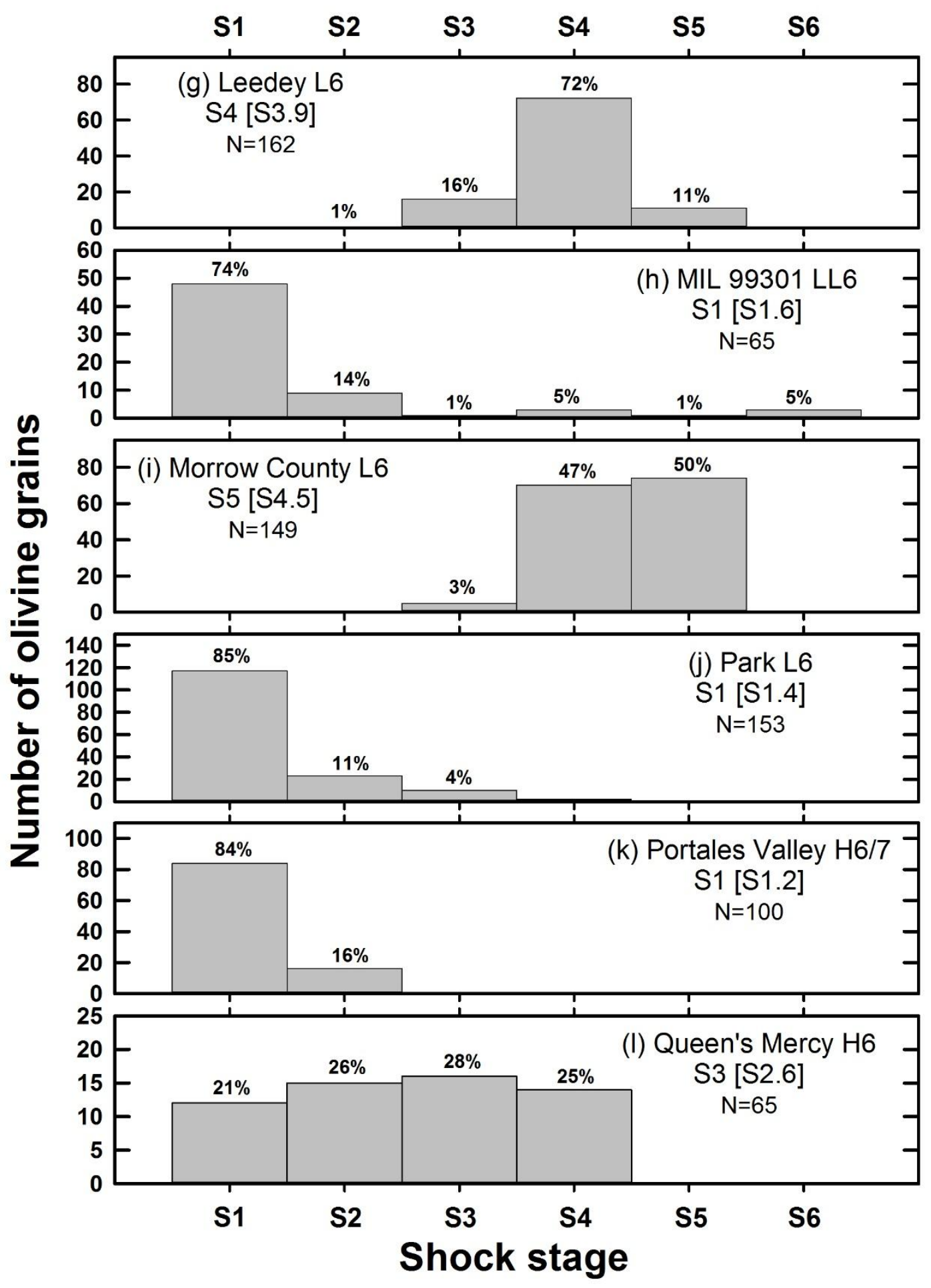

1066 
1067

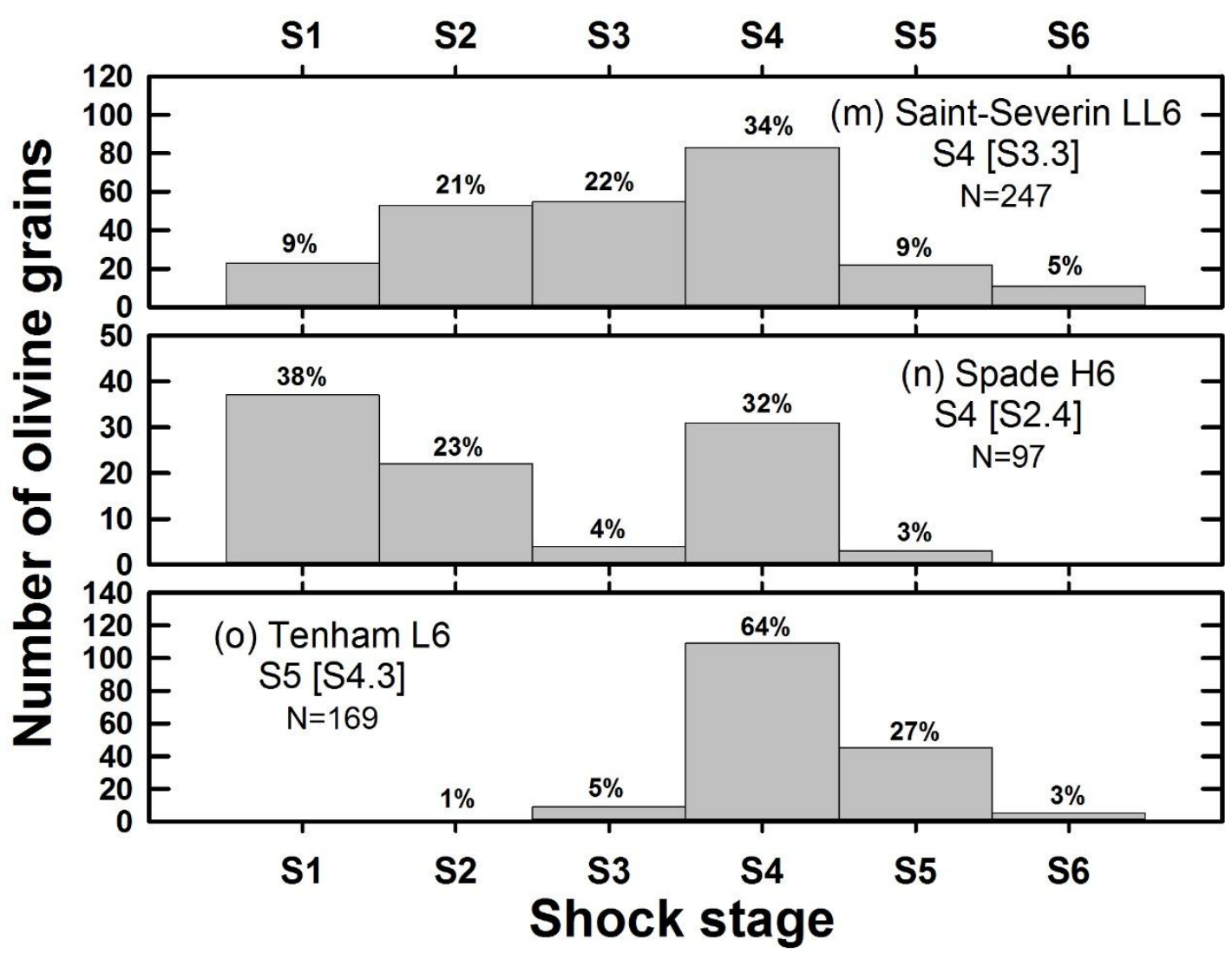


$1070 \quad$ Fig. 3.

1071
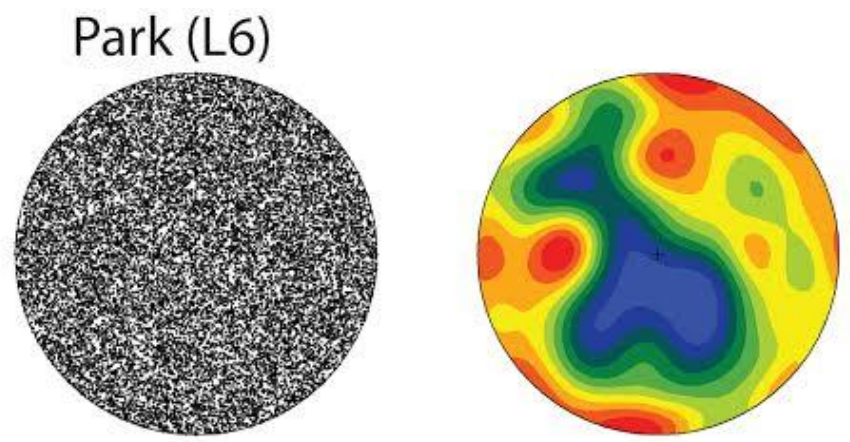

shock stage $\mathrm{S} 1$

(weighted 1.35)

$\mathrm{C}=0.04$

$\mathrm{n}=22347$

Spade (H6)
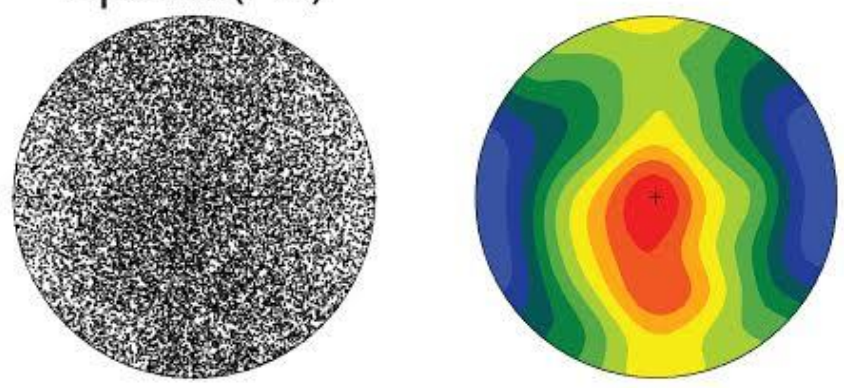

shock stage S4

(weighted 2.39)

$C=0.30$

$\mathrm{n}=20535$

Bruderheim (L6)
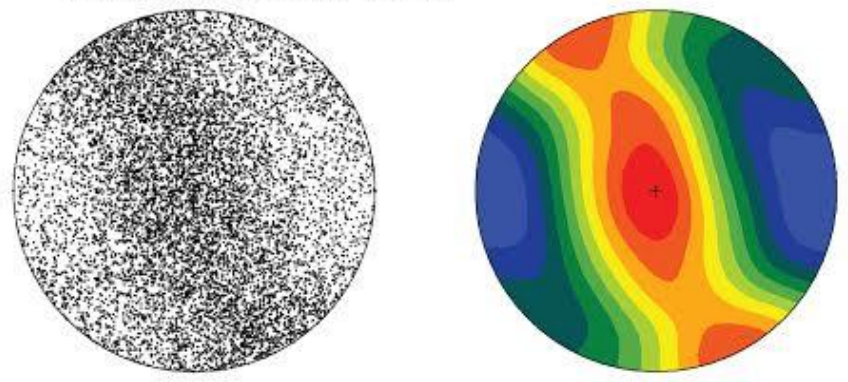

shock stage $\$ 4$

(weighted 3.78)

$C=0.56$

$\mathrm{n}=10600$

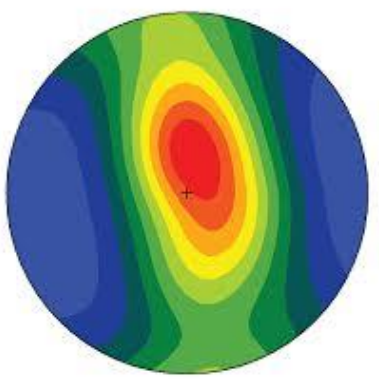

shock stage S5

(weighted 4.18)

$C=1.13$

$\mathrm{n}=22392$ 
1073

1074

Fig. 4.
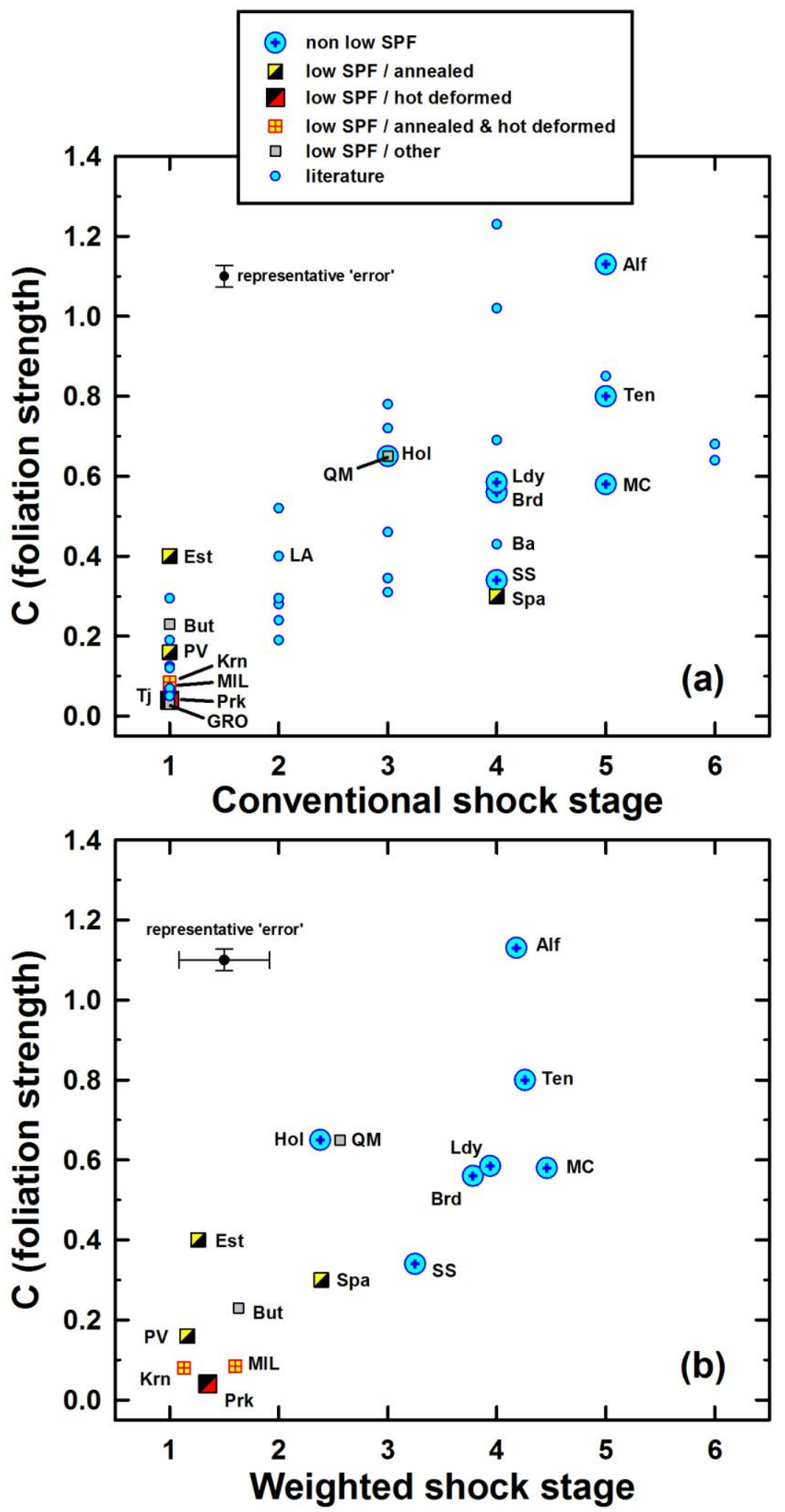
1078

1079

1080

Fig. 5.
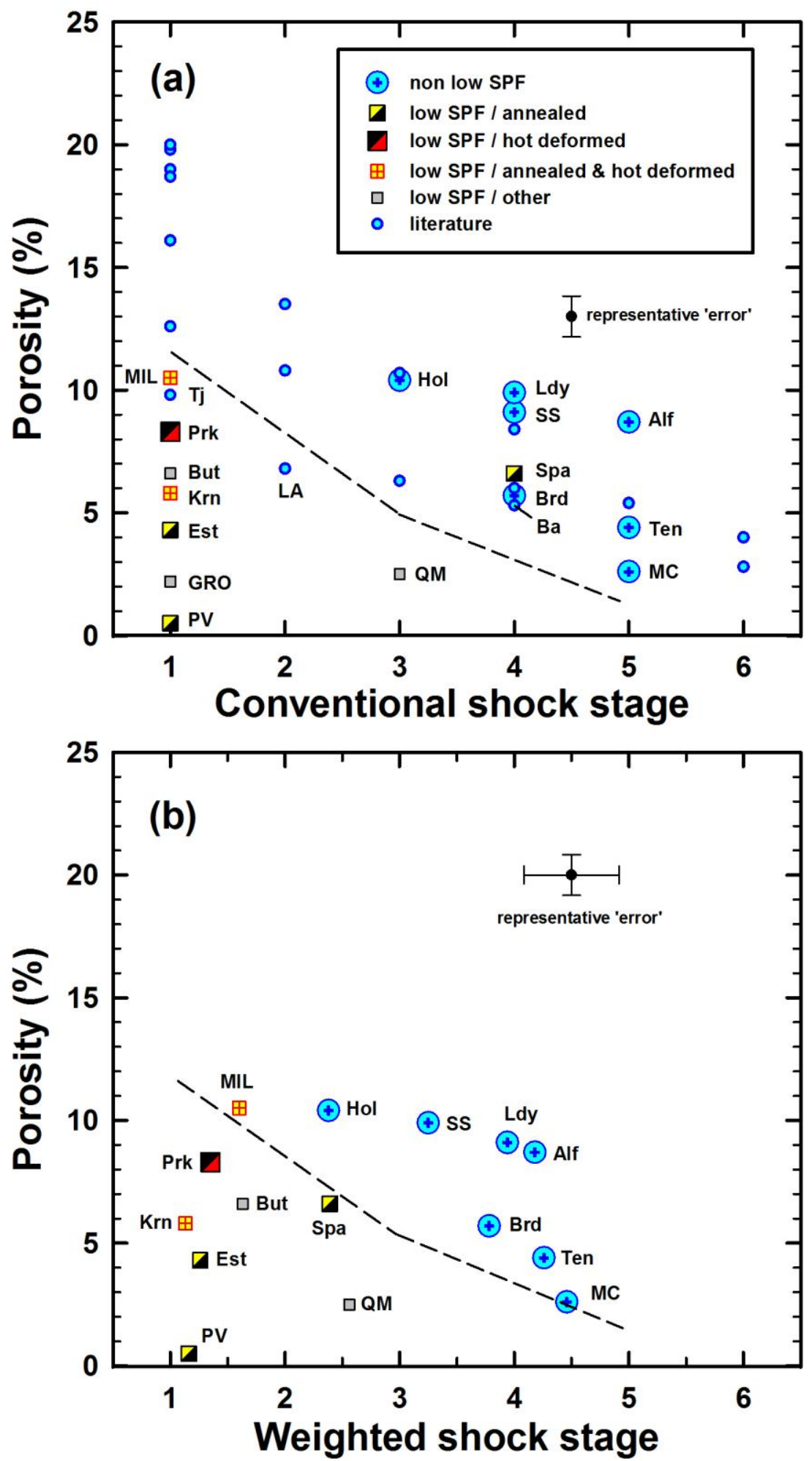
1083 Fig. 6.

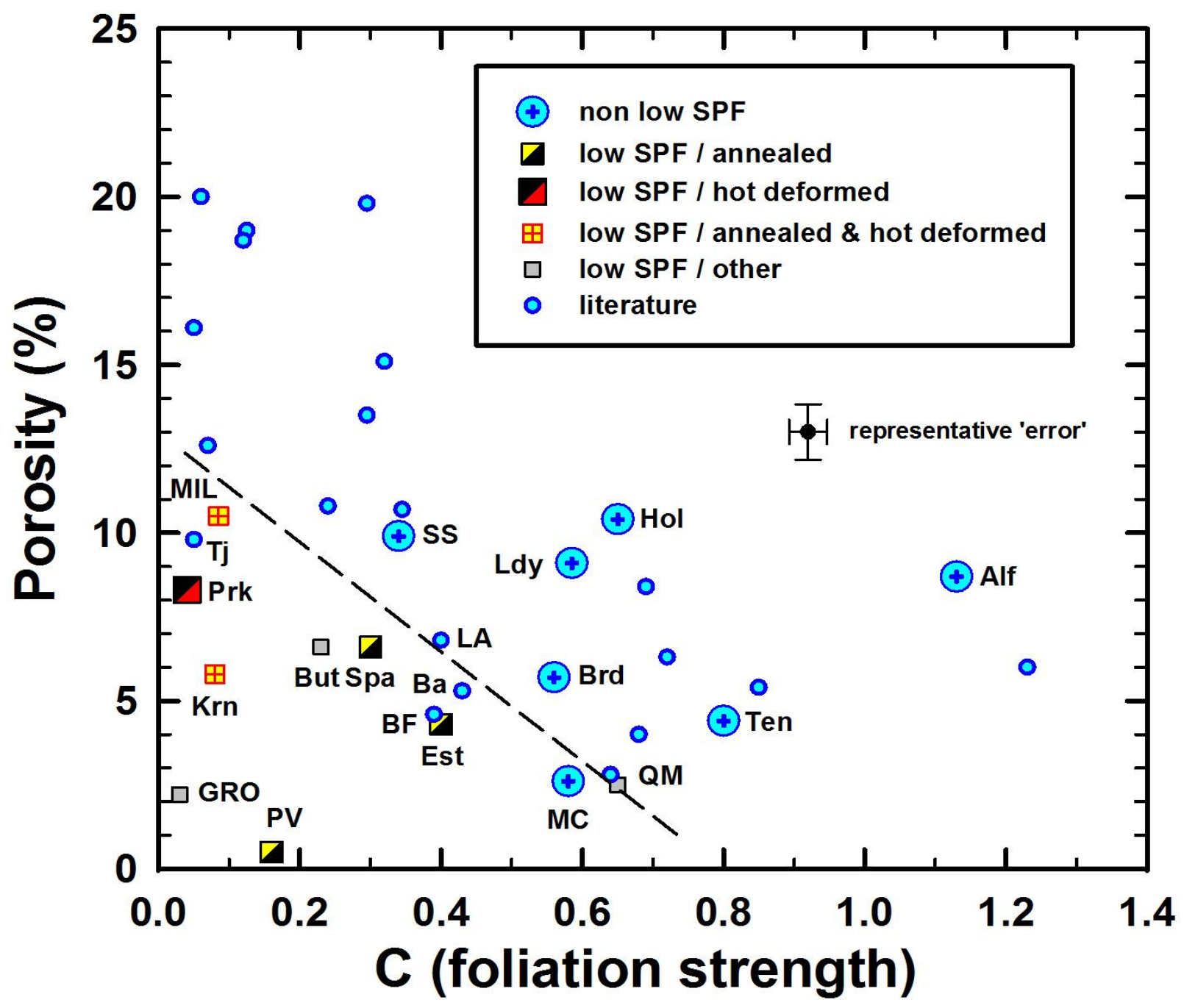

1085 